Article

\title{
An Easy Procedure to Quantify Anticoagulant Rodenticides and Pharmaceutical Active Compounds in Soils
}

\author{
Andrea Acosta-Dacal 1,+(i) Cristian Rial-Berriel ${ }^{1,+(\mathbb{D})}$, Ricardo Díaz-Díaz ${ }^{2}$, María del Mar Bernal-Suárez ${ }^{2}$, \\ Manuel Zumbado ${ }^{1,3}$, Luis Alberto Henríquez-Hernández ${ }^{1,3} \mathbb{1}^{-}$and Octavio P. Luzardo ${ }^{1,3, *}$ \\ 1 Toxicology Unit, Research Institute of Biomedical and Health Sciences (IUIBS), Universidad de Las Palmas de \\ Gran Canaria, Paseo Blas Cabrera s/n, 35016 Las Palmas de Gran Canaria, Spain; \\ andrea.acosta@ulpgc.es (A.A.-D.); cristian.rial@ulpgc.es (C.R.-B.); manuel.zumbado@ulpgc.es (M.Z.); \\ luis.henriquez@ulpgc.es (L.A.H.-H.) \\ 2 Department of Environmental Analysis, Technological Institute of the Canary Islands, C/Los Cactus No 68, \\ Polígono Industrial de Arinaga, Agüimes, 35118 Las Palmas, Spain; rdiaz@itccanarias.com (R.D.-D.); \\ mbernal@itccanarias.org (M.d.M.B.-S.) \\ 3 Spanish Biomedical Research Center in Physiopathology of Obesity and Nutrition (CIBERObn), Instituto de \\ Salud Carlos III, 28029 Madrid, Spain \\ * Correspondence: octavio.perez@ulpgc.es; Tel.: +34-928-451-424; Fax: +34-928-451-416 \\ + These authors contributed equally to the work, and therefore should be considered indistinctly as \\ first authors.
}

check for

updates

Citation: Acosta-Dacal, A.; Rial-Berriel, C.; Díaz-Díaz, R.; Bernal-Suárez, M.d.M.; Zumbado, M.; Henríquez-Hernández, L.A.; Luzardo, O.P. An Easy Procedure to Quantify Anticoagulant Rodenticides and Pharmaceutical Active Compounds in Soils. Toxics 2021, 9, 83. https:// doi.org/10.3390/toxics 9040083

Academic Editor: James Longstaffe

Received: 8 March 2021

Accepted: 7 April 2021

Published: 10 April 2021

Publisher's Note: MDPI stays neutral with regard to jurisdictional claims in published maps and institutional affiliations.

Copyright: (c) 2021 by the authors. Licensee MDPI, Basel, Switzerland. This article is an open access article distributed under the terms and conditions of the Creative Commons Attribution (CC BY) license (https:/ / creativecommons.org/licenses/by/ $4.0 /)$.

\begin{abstract}
A modified QuEChERS (quick, easy, cheap, effective, rugged, and safe) extraction was validated for the extraction of seven coumarin anticoagulant rodenticides (ARs) and 36 pharmaceutical active compounds (PhACs) residues in soil samples using liquid chromatography tandem mass spectrometry (LC-MS/MS). The aim of this work was to develop a method for the monitoring of these compounds in agricultural lands as well as in forensic applications for the determination of ARs poisoning. As far as is known, this is the first time that a QuEChERS-based method is used for the extraction of ARs in soil, as well as on such a quantity of PhACs. A matrix effect study was carried out on samples of soil devoted to agriculture in the midland area of the Canary Islands (clay loam type). It was in house validated (accuracy, precision, and linearity) at seven spiked levels between 0.5 and $50 \mathrm{ng} \mathrm{g}^{-1}$. The limits of quantification (LOQ) ranged between 0.5 and $50.0 \mathrm{ng} \mathrm{g}^{-1}$ and the limits of detection (LOD) ranged from 0.024 to $6.25 \mathrm{ng} \mathrm{g}^{-1}$. The method was then successfully used for both the determination of the target analytes in the soils from the agricultural plots that had been irrigated with regenerated water, and in the soil collected from underneath wild bird carcasses (which had been the subject of forensic investigation).
\end{abstract}

Keywords: brodifacoum; flocoumafen; veterinary drugs; QuEChERS; LC-MS/MS; forensic analysis

\section{Introduction}

Soil is a very vulnerable pollution receptor environment from where pollutants can be emitted to other environmental compartments such as the atmosphere, ground or surface water, and biota [1]. Contaminated soil presents a large number of problems that may include the destruction of ecosystems, agricultural productivity losses, the contamination of groundwater, and danger to human and animal life due to the accidental ingestion of soil or consumption of food that has grown on contaminated soil. Agricultural soil contamination can be direct and intended, thorough the application of pesticides to crops, or indirect and nonintended, mainly due to irrigation using regenerated waters and the use of compost of wastewater treatment plants (WWTPs) sludge. Both water and sewage sludge may contain various contaminants of emerging concern (CECs), including anticoagulant rodenticides (ARs) and pharmaceutical active compounds (PhACs).

ARs are the most widely used rodent control agent in agriculture (usually in postharvest plants and warehouses), livestock farming, and in domestic and urban applications [2]. 
These substances act by preventing the formation of clotting factors by blocking the vitamin K cycle and, thus, causing spontaneous internal bleeding [3]. The first generation of ARs (FGARs) started with warfarin, soon followed by coumatetralyl, chlorophacinone, and diphacinone [4]. Following the widespread development of rodent resistance to FGARs, a second and more toxic generation of compounds (SGARs), including flocoumafen, difethialone, difenacoum, bromadiolone and brodifacoum, were developed in the 1970s [5]. On the other hand, some anticoagulants, such as warfarin or its analogues, are used in the medical treatment of blood hypercoagulability disorders [6]. Taking this into account, ARs can reach wastewater through runoff after agricultural and livestock farming applications, bait solubilization in urban infrastructures or through urinary excretion from medical treatments $[7,8]$.

PhACs are essential for the prevention and treatment of disease in humans and animals $[9,10]$. After administration, these active substances are absorbed and can be either metabolized or converted back into active ingredients [11]. A part of them is excreted through urine or feces, and may enter WWTPs and end up in environmental compartments as both metabolites and parent compounds [12,13]. The presence of PhACs in the environment can favor the appearance and the development of various adverse effects, such as antibiotic-resistant microorganisms, even at low levels due to continuous exposure to antimicrobials [13].

Once in WWTPs, both ARs and PhACs can be degraded, accumulate in sewage sludge or remain in the water, even after tertiary treatments, which are released to effluent receiving waters or used to irrigate crops [14]. In addition, due to their hydrophobicity, ARs are more likely to accumulate in sewage sludge, which is commonly used to make compost [15] while PhACs can be found in both media depending on their physicochemical properties [16]. Similarly, ARs are relatively stable and have a moderate to high octanol/water partition coefficient ( $\left.\mathrm{K}_{\mathrm{OW}}\right)$ allowing them to associate with natural soil organic matter $[17,18]$. As for the fate of PhACs, depending on their interaction with soil matrix components, they may remain in or be transported to groundwater and surface water through surface runoff, infiltration/percolation [12,19]. As seen, the amounts of ARs and PhACs that may eventually accumulate in soils through irrigation with regenerated wastewater and/or through sludge and manure spreading or from direct bait application on fields, should be a matter of concern.

Both PhACs and ARs may pose a high risk to wildlife due to their potential for bioaccumulation and transfer through trophic webs. Although ARs are intended to control rodents, baits may be consumed by other nontarget species such as granivorous birds (primary exposure). Similarly, predators or scavengers may consume rodents and nontarget animals that have already been exposed to ARs (secondary exposure) [20]. Moreover, ARs baits are often intentionally used to poison and kill not rodents but other animals. Likewise, the exposure of wild animals to PhACs can occur in several ways: contaminated water [21], agricultural soils, plants and arthropods [22,23]. The carcasses of farm animals that have been previously medicated, as well as their slurry, can also be a relevant source of exposure to pollutants for wildlife $[16,24]$. In such cases, exposure is usually monitored by blood or liver tissue samples from dead animals $[25,26]$. However, it is quite usual to find only the remains of animal carcasses and not being able to collect tissue or fluid samples. Therefore, for these specific cases, an extraction method to test the soil sampled under the carcass may be an appropriate way to prove exposure to these compounds due to the capacity of the soil organic matter to retain them after being leached from the carcasses.

There are very few studies on extraction methods for anticoagulants in soils [27-32] and, to our knowledge, none of them use the QuEChERS methodology. Although there are more methods of extracting PhACs from soils, only a small number of them use QuEChERS procedures [33-36]. The QuEChERS method consists of an acetonitrile extraction/partitioning step followed by a solid-phase dispersive extraction as a clean-up step and was first developed for the extraction of pesticides from fruits and vegetables [37]. This user-friendly methodology provides high extraction yields using reduced amounts of sam- 
ples and organic solvents, which has led to its use in different matrices and analytes [38]. Modified versions of QuEChERS have been successfully applied in soils for the extraction of organic contaminants, including pesticides [39-41], persistent organic pollutants [42,43], as well as in the extraction of ARs and PhACs from other samples such as food [44,45], blood [46,47], sediments and sludge [48], and the liver [49,50].

Along with a robust extraction method, adequate detection analysis is necessary. ARs and PhACs have been determined mainly by liquid chromatography (LC) with different detectors such as UV [32,51], diode array (DAD) [30,52], DAD with fluorescence detectors (FLD) $[53,54]$ and single quadruple mass spectrometry (MS) detectors $[28,55]$. However, the preferred option when looking for sensitivity and selectivity at trace level is liquid chromatography-tandem mass spectrometry (LC-MS/MS) $[7,35,56,57]$, which is the best option for low-level residues that can be expected to be found in soils.

The objective of this research was to evaluate and validate a QuEChERS-based and LC-MS/MS method for the quantification of ARs and PhACs in soils, as well as their verification in samples of agricultural origin and from wildlife carcasses. The work is proposed as a scope extension of the previously optimized method for the quantification of pesticide residues in soils [41]. The proposed method can be applied in agricultural, environmental and forensic monitoring.

\section{Materials and Methods}

\subsection{Reagents and Chemicals}

Individual certified standards of ARs and PhACs (purity 95.19\% to 99.9\%) were acquired from Dr. Ehrenstorfer (Augsburg, Germany), Sigma-Aldrich (Augsburg, Germany) and European Pharmacopoeia Reference Standards (Strasbourg, France). Atrazine-d5, Carbendazim-d3, Coumachlor, Cyromazine-d4, Linuron-d3 and Pirimicarb-d6 (Dr. Ehrenstorfer and Sigma-Aldrich, 99.3-99.9\% purity) were used as procedural internal standards (P-IS) and were maintained as described in the reference method [41]. These internal standards were added to the samples at the beginning of the procedure to account for various sources of errors throughout all stages in the method [58]. The list of the selected analytes, their classification, and their legal status are in Table 1.

LC-MS grade methanol (MeOH), acetonitrile (ACN) and formic acid (FA, $\mathrm{HCOOH})$ were obtained from Honeywell (Morristown, NJ, USA). Ammonium acetate $\left(\mathrm{NH}_{4} \mathrm{CH}_{3} \mathrm{CO}_{2}\right)$ was purchased from Fisher Scientific (Loughborough, UK). AOAC method QuEChERS salts [59] ( $6 \mathrm{~g}$ of $\mathrm{MgSO}_{4}$ and $1.5 \mathrm{~g}$ of $\mathrm{CH}_{3} \mathrm{COONa}$ ) were acquired in commercial premixes from Agilent Technologies (Palo Alto, CA, USA). The ultrapure water was produced in the laboratory using a Gradient A10 Milli-Q System (Millipore, Bedfore, MA, USA).

\subsection{Standard Stock Solutions and Mixes}

Individual standard stock solutions of all analytes and P-IS were prepared in ACN at a concentration of $1000 \mu \mathrm{g} \mathrm{mL}^{-1}$. Individual intermediate solutions of $1 \mu \mathrm{g} \mathrm{mL} L^{-1}$ were prepared for spectrometry optimization. In addition, two mixed stock solutions were prepared, one containing target ARs and the other containing the selected PhACs, at $10 \mu \mathrm{g} \mathrm{mL}^{-1}$ followed by a mixed working solution diluted ten times more than $1 \mu \mathrm{g} \mathrm{mL}^{-1}$ of each. Finally, a P-IS solution was prepared at $1 \mu \mathrm{g} \mathrm{mL} \mathrm{m}^{-1}$.

Both solvent and matrix-matched calibration curves were prepared with the standard working mix solution in either soil extracted with the evaluated procedure or ACN $2.5 \%$ FA diluted with ultrapure water $(1: 1, v / v)$.

All standards, working mix solutions and matrix-matched calibrators were stored in glass amber vials at $-20^{\circ} \mathrm{C}$ and checked periodically for stability.

\subsection{Sample Selection and Pretreatment}

The extraction method was validated on a representative type of soil, which due to its physicochemical properties, can be classified as clay loam soil. The soil was chosen from two farms dedicated to organic production and sampled at various times throughout 2020. 
A composite sample of at least four subsamples collected at depths between 20 and $30 \mathrm{~cm}$ was prepared in each sampling plot. It was then thoroughly mixed and homogenized, air-dried at room temperature and sieved ( $2 \mathrm{~mm}$ mesh) before being considered suitable for analysis.

The physicochemical properties of this composite are as follows: $\mathrm{pH} 4.88$, electrical conductivity $209 \mu \mathrm{S} \mathrm{cm} \mathrm{cm}^{-1}$, oxidizable organic carbon $2.19 \%$ (approximately $3.9 \%$ organic matter), $6 \%$ moisture and particle size distribution: $29.5 \%$ clay, $28.3 \%$ fine silt, $11.3 \%$ thick slit, $11.5 \%$ coarse sand, and $19.4 \%$ fine sand. All these parameters were determined in the facilities of the Department of Department of Animal Biology, Edaphology and Geology of the University of La Laguna (Tenerife, Spain) [41].

\subsection{Sample Preparation}

The method used for the extraction of the target analytes was previously developed and validated in our laboratory for the extraction of pesticides in clay loam soil $[41,60]$. In summary, the samples were prepared by weighing $10 \pm 0.05 \mathrm{~g}$ of dried and sieved soil into a $50 \mathrm{~mL}$ centrifuge. All samples were spiked with the appropriate volume of the P-IS solution to achieve a concentration of $5 \mathrm{ng} \mathrm{g}^{-1}$, and recoveries and Quality Controls (QCs) were added standard mix solutions and left to stand for $1 \mathrm{~h}$ prior to extraction. Then, $10 \mathrm{~mL}$ of ACN-2.5\% FA were added and vigorously shaken for $1 \mathrm{~min}$. In the same way, $6 \mathrm{~g}$ of $\mathrm{MgSO}_{4}$ and $1.5 \mathrm{~g}$ of $\mathrm{CH}_{3} \mathrm{COONa}$ were added, energetically shaken for another minute and sonicated for $15 \mathrm{~min}$ in an ultrasonic bath operating at 50/60 Hz and $120 \mathrm{~W}$ (VWR, Radnor, PA, USA). After that, samples were placed $25 \mathrm{~min}$ in a rotatory shaker (Ovan, Barcelona, Spain). They were then centrifuged for $10 \mathrm{~min}$ at $4200 \mathrm{rpm}(3175.16 \times g)$ in a $5804 \mathrm{R}$ Eppendorf centrifuge (Eppendorf, Hamburg, Germany). An aliquot of the supernatant extract was filtered through $0.20 \mu \mathrm{m}$ Chromafil ${ }^{\circledR}$ PET filters (Macherey-Nagel, Düren, Germany) and diluted with $\mathrm{H}_{2} \mathrm{O}(1: 1, v / v)$ before analysis in LC-MS/MS.

\subsection{LC-MS/MS Analysis}

LC-MS/MS equipment (1290 model UPLC tandem coupled to a 6460 model Triple Quadrupole mass spectrometer, Agilent Technologies, Palo Alto, CA, USA). The chromatographic column was an Agilent Poroshell 120 EC-C18 $(2.1 \times 100 \mathrm{~mm}, 2.7 \mu \mathrm{m})$, with a guard precolumn $(2.1 \times 5 \mathrm{~mm}, 1.8 \mu \mathrm{m})$ plus a and prefilter. The column oven was set at $50{ }^{\circ} \mathrm{C}$. The mobile phases consisted of $2 \mathrm{mM}$ ammonium acetate $0.1 \%$ formic acid in ultrapure water (A) and $2 \mathrm{mM}$ ammonium acetate in $\mathrm{MEOH}(\mathrm{B})$. The binary gradient was set as follows: 5\% B-0.5 min; 5\% B-1 min; 40\% B-2.5 min; 85\% B-8 $\mathrm{min} ; 100 \%$ B-10 to $14 \mathrm{~min} ; 5 \%$ $\mathrm{B}-14.01 \mathrm{~min}$. The flow rate was $0.4 \mathrm{~mL} \mathrm{~min}^{-1}$. The volume injected was $5 \mu \mathrm{L}$ and the total run time was $18 \mathrm{~min}$.

The parameter for the MS/MS analyzer were those described in the original method [41]. Data analysis was performed using Agilent software MassHunter Quantitative Analysis (for QQQ) version B.07.01 and MassHunter Qualitative Analysis version B.07.00.

The MS/MS conditions were optimized by injecting $5 \mu \mathrm{L}$ of individual solutions of each compound at $1 \mu \mathrm{g} \mathrm{mL}^{-1}$ in ACN directly to the mass spectrometer replacing the chromatographic column with a stainless steel zero dead volume union. The mobile phases were set in isocratic mode (50:50, v/v), and these were $2 \mathrm{mM}$ ammonium acetate and $0.1 \%$ FA in ultrapure water (phase A) and $2 \mathrm{mM}$ ammonium acetate and $0.1 \%$ FA in methanol (B). The product ions were optimized in the MRM mode at different collision energies, from which that exhibiting the highest response was selected.

\subsection{In House Validation Parameters}

To validate the use of the proposed method and broaden it to the selected ARs and PhACs, we performed a single-laboratory validation. Since there is no a specific guidance for the analysis of ARs and PhACs residues in soil, the in house validation (hereafter validation) of the proposed method was performed following the guidelines for the analysis of pesticide residues in food and feed of the European Union [58,61]. 
The linear range of LC-MS/MS method was studied using calibration curves prepared in soil matrix-water $(1: 1, v / v)$, ranging from 0.024 to $50 \mathrm{ng} \mathrm{g}^{-1}$ using both correlation coefficient and Mandel test (95\% confidence level) [62]. Accuracy was estimated by recovery assays (in quintuplicate) through the quantification of trueness and precision (\% relative standard deviation) at 7 concentration levels: $0.5,1,2.5,5,10,20$ and $50 \mathrm{ng} \mathrm{g}^{-1}$. According to the SANTE and SANCO guides, recoveries between $70-120 \%$ are considered acceptable, when the RSDs are below $20 \%$. Additionally, following the criteria specified in those guides the limit of quantification (LOQ) for each compound was the lowest level of the recovery experiments that met all the validation criteria: recovery between $80-120 \%$, and RSD below $20 \%$. On the other hand, the limits of detection (LOD) were calculated using calibration standards. For this purpose, triplicate matrix-matched calibration curves were prepared ranging from 0.024 to $100 \mathrm{ng} \mathrm{g}^{-1}$. Thus, the LOD was selected as the lowest point of the calibration curve that meets had a signal-to-noise ratio $(\mathrm{S} / \mathrm{N})>3$ (Peak-to-Peak algorithm) and an accuracy between $80-120 \%$.

The identity of the compounds was based on the acquisition of two transitions in the MRM mode, one of them employed as the quantification transition $(Q)$, and the other as the confirmation transition (q). According to the SANTE and SANCO guides an ion ratio tolerance of $30 \%$ was considered acceptable. The tolerance for the deviation of the retention time $(\mathrm{tR}) \pm 0.1$ with respect to that of the reference standard.

\section{Results and Discussion}

\subsection{Optimization of LC-MS/MS Conditions}

The seven target rodenticides, chloramphenicol, tolfenamic acid, and the P-IS coumachlor were determined in negative mode with precursor ions corresponding to $[\mathrm{M}-\mathrm{H}]^{-}$. The remaining analytes and P-IS were analyzed in positive mode using precursor ions corresponding to $[\mathrm{M}+\mathrm{H}]^{+}$except for cefuroxime axetil, cloxacillin, eprinomectin, josamycin and penicillin V. It is known that, together with the protonated and deprotonated molecules already mentioned, the ionization process can produce a variety of adduct ions depending on the composition and concentration of mobile-phase additives and analytes, the $\mathrm{pH}$, the mobile-phase flow rate, the temperature or even solvent impurities and glassware [63-65]. While cefuroxime axetil formed a sodium adduct $[\mathrm{M}+\mathrm{Na}]^{+}$, cloxacillin, josamycin and penicillin $\mathrm{V}$ formed methanol adducts, which was the organic phase solvent. In the case of eprinomectin, the ion $m / z 878$ selected as parental for both transitions is its protonated derivative ion resulting from dehydrative aromatization [66]. In the case of brodifacoum and bromadiolone, which have $\mathrm{Br}$ in their chemical structures, an element with an abundant characteristic isotope distribution, transitions corresponding to ${ }^{79} \mathrm{Br}$ and ${ }^{81} \mathrm{Br}$ were selected. In the same way, chloramphenicol, which has two atoms of $\mathrm{Cl}$ in its structure, was optimized selecting the transitions corresponding to ${ }^{35} \mathrm{Cl}$ and ${ }^{37} \mathrm{Cl}$. The transitions were chosen in terms of selectivity and sensitivity, selecting the most abundant ones for quantification proposals.

The parameters of the ion source were then optimized injecting standards at $100 \mathrm{ng}$ $\mathrm{mL}^{-1}$ in ACN (in triplicate). The parameters were nebulizer and sheath gas flow and temperature, and capillary and nozzle voltages. The Agilent software (Mass Hunter Source Optimizer) was employed for this purpose.

Likewise, we also injected $20 \mathrm{ng} \mathrm{mL}^{-1}$ standards in triplicate, prepared in the same solvent, for the chromatographic condition optimization process. The final conditions selected for both the source and the chromatography were then tested with a matrix-matched standard at the same concentration. We decided to use Poroshell 120 EC-C18 column $(2.1 \times 100 \mathrm{~mm}, 2.7 \mu \mathrm{m}$; Agilent Technologies $)$ due to the satisfactory performance for the variety of pesticide belonging to different chemical groups optimized in the previous work [41]. The mobile phase solvents and modifiers used for the compound optimization process were also set as the final phase composition to ensure the formation of the mentioned adducts. However, different concentrations and gradients of ammonium acetate (2 and $5 \mathrm{mM}$ ) and FA (none and $0.1 \%$ ) were tested to achieve the best resolution and sepa- 
ration of the compounds. A higher amount of ammonium not only did not improve the sensitivity, but also increased the pressure in the column, so it was set as $2 \mathrm{mM}$. However, we eliminated FA from the organic phase as it worsens the sensitivity of ARs compounds, but we continued to use it in the aqueous phase because it was necessary for the analysis of some PhACs. This decision was made because ARs retention starts with warfarin at $7.87 \mathrm{~min}$ (with this combination of mobile phases and gradient) where the organic mobile phase is approximately $83 \%$ and continues to increase. This way, the acid composition in the column will decrease when the ARs are retained in the column.

The injection volume was set at $5 \mu \mathrm{L}$ after testing from 1 to $20 \mu \mathrm{L}$ because it produced good peak shapes while giving high responses. In addition, a higher volume would result in saturation of the MS/MS detector. The possible dilution of the extract with water was also evaluated at this point before injecting it in the LC-MS/MS equipment. The ratios tested were 1:1, 1:2, 1:5 y 1:10 (v/v) of $20 \mathrm{ng} \mathrm{g}^{-1}$ standards in ACN-2.5\%FA-ultrapure water. The experiment was then repeated with standards in the soil matrix at the same dilutions. In order to achieve considerable sensitivity and selectivity, while improving the peak shape of some compounds such as chloramphenicol, dexamethasone and mebendazole, we chose to dilute the final extract $1: 1, v / v$ with water.

All the chromatography and mass spectrometry conditions are shown in Table 1 . In addition, a chromatogram of a blank soil sample spiked at $50 \mathrm{ng} \mathrm{g}^{-1}$ is shown in Figure 1.

Table 1. Characterization of target compounds by therapeutical classes or biocides, legal status, and their chromatographic and mass spectrometric conditions.

\begin{tabular}{|c|c|c|c|c|c|c|c|c|c|c|}
\hline \multirow[b]{2}{*}{$\mathbf{N}^{\circ}$} & \multirow[b]{2}{*}{ Compound } & \multirow[b]{2}{*}{ Category $^{a}$} & \multirow[b]{2}{*}{$\begin{array}{l}\text { Legal Status } \\
\text { in the EU }\end{array}$} & \multirow[b]{2}{*}{$\underset{(\min )}{\mathrm{tR}}$} & \multirow[b]{2}{*}{ Polarity } & \multicolumn{2}{|c|}{ Quantification } & \multicolumn{2}{|c|}{ Confirmation } & \multirow[b]{2}{*}{$\begin{array}{c}\text { Fragmentor } \\
\text { Voltage } \\
\text { (V) }\end{array}$} \\
\hline & & & & & & $\begin{array}{c}\text { MRM } \\
\text { Transition } \\
(m / z)\end{array}$ & $\begin{array}{c}\mathrm{CE} \\
(\mathrm{eV})\end{array}$ & $\begin{array}{c}\text { MRM } \\
\text { transition } \\
(m / z)\end{array}$ & $\begin{array}{l}\mathrm{CE} \\
(\mathrm{eV})\end{array}$ & \\
\hline 1 & Sulfanilamide & PhACs, AB & Approved & 1.06 & Positive & $173.0 \rightarrow 93.0$ & 24 & $173.0 \rightarrow 76.1$ & 50 & 126 \\
\hline 2 & Sulfacetamide & PhACs, AB & Approved & 2.28 & Positive & $215.3 \rightarrow 92.0$ & 20 & $215.3 \rightarrow 65.3$ & 45 & 90 \\
\hline 3 & Metronidazole & PhACs, AB & Approved & 2.73 & Positive & $172.1 \rightarrow 128.0$ & 12 & $172.1 \rightarrow 82.1$ & 24 & 98 \\
\hline 4 & Sulfadiacine & PhACs, AB & Approved & 2.82 & Positive & $251.0 \rightarrow 92.0$ & 28 & $251.0 \rightarrow 156.0$ & 12 & 111 \\
\hline 5 & Sulfapyridine & PhACs, AB & Approved & 3.16 & Positive & $250.0 \rightarrow 92.0$ & 28 & $250.0 \rightarrow 156.0$ & 12 & 126 \\
\hline 6 & Sulfameracine & PhACs, AB & Not approved & 3.29 & Positive & $265.0 \rightarrow 92.0$ & 28 & $265.0 \rightarrow 156.0$ & 12 & 126 \\
\hline 7 & Sulfametizole & PhACs, AB & Not approved & 3.59 & Positive & $271.0 \rightarrow 155.9$ & 8 & $271.0 \rightarrow 92.0$ & 28 & 103 \\
\hline 8 & Sulfametacine & PhACs, AB & Not approved & 3.68 & Positive & $279.1 \rightarrow 186.0$ & 12 & $279.1 \rightarrow 92.0$ & 32 & 134 \\
\hline 9 & Sulfametoxipiridacine & PhACs, AB & Not approved & 3.76 & Positive & $281.0 \rightarrow 155.9$ & 12 & $281.0 \rightarrow 92.1$ & 28 & 121 \\
\hline 10 & Sulfachloropiridacine & PhACs, AB & Not approved & 3.89 & Positive & $285.0 \rightarrow 156.0$ & 12 & $285.0 \rightarrow 92.1$ & 28 & 101 \\
\hline 11 & Sulfametoxazole & PhACs, AB & Approved & 3.95 & Positive & $254.0 \rightarrow 92.0$ & 28 & $254.0 \rightarrow 156.0$ & 12 & 111 \\
\hline 12 & Sulfamonomethoxine & PhACs, AB & Not approved & 4.02 & Positive & $281.1 \rightarrow 92.1$ & 14 & $281.1 \rightarrow 156.0$ & 32 & 120 \\
\hline 13 & Sulfadoxine & PhACs, AB & Approved & 4.13 & Positive & $311.1 \rightarrow 156.0$ & 16 & $311.1 \rightarrow 92.0$ & 32 & 126 \\
\hline 14 & Sulfisoxazole & PhACs, AB & Not approved & 4.14 & Positive & $268.0 \rightarrow 156.0$ & 8 & $268.0 \rightarrow 92.1$ & 24 & 106 \\
\hline 15 & Chloramphenicol & PhACs, AB & Approved & 4.76 & Negative & $321.0 \rightarrow 152.1$ & 4 & $323.0 \rightarrow 152.1$ & 4 & 113 \\
\hline 16 & Sulfadimetoxine & PhACs, AB & Approved & 4.83 & Positive & $311.0 \rightarrow 156.0$ & 16 & $311.0 \rightarrow 92.0$ & 32 & 139 \\
\hline 17 & Sulfaquinoxaline & PhACs, AB & Approved & 4.99 & Positive & $301.0 \rightarrow 156.0$ & 12 & $301.0 \rightarrow 92.1$ & 32 & 159 \\
\hline 18 & $\begin{array}{l}\text { Cefuroxime axetil } \\
\text { (two isomers) }\end{array}$ & PhACs, AB & Approved & 5.40 & Positive & $533.0 \rightarrow 447.0$ & 15 & $533.0 \rightarrow 386.0$ & 20 & 160 \\
\hline 19 & Oxfendazole & PhACs, AH & Approved & 5.64 & Positive & $316.1 \rightarrow 159.0$ & 32 & $316.1 \rightarrow 191.1$ & 16 & 166 \\
\hline 20 & Penicillin V & PhACs, AB & Approved & 6.48 & Positive & $383.2 \rightarrow 159.9$ & 10 & $383.2 \rightarrow 113.9$ & 40 & 130 \\
\hline 21 & Mebendazole & PhACs, AH & Approved & 6.73 & Positive & $296.1 \rightarrow 264.1$ & 20 & $296.1 \rightarrow 77.0$ & 48 & 151 \\
\hline 22 & Cloxacillin & PhACs, AB & Approved & 7.09 & Positive & $468.1 \rightarrow 159.9$ & 8 & $468.1 \rightarrow 177.8$ & 20 & 126 \\
\hline 23 & Dexamethasone & PhACs, GC & Approved & 7.18 & Positive & $393.2 \rightarrow 373.2$ & 2 & $393.2 \rightarrow 355.2$ & 6 & 103 \\
\hline 24 & Albendazole & PhACs, AH & Approved & 7.27 & Positive & $266.1 \rightarrow 234.1$ & 16 & $266.1 \rightarrow 191.0$ & 32 & 155 \\
\hline 25 & Ketoprofen & $\begin{array}{l}\text { PhACs, } \\
\text { NSAID }\end{array}$ & Approved & 7.36 & Positive & $255.1 \rightarrow 209.1$ & 8 & $255.1 \rightarrow 77.1$ & 48 & 123 \\
\hline 26 & Josamycin & PhACs, AB & Approved & 7.52 & Positive & $860.5 \rightarrow 173.9$ & 40 & $860.5 \rightarrow 108.9$ & 40 & 200 \\
\hline
\end{tabular}


Table 1. Cont.

\begin{tabular}{|c|c|c|c|c|c|c|c|c|c|c|}
\hline \multirow[b]{2}{*}{$\mathbf{N}^{\circ}$} & \multirow[b]{2}{*}{ Compound } & \multirow[b]{2}{*}{ Category $^{a}$} & \multirow[b]{2}{*}{$\begin{array}{l}\text { Legal Status } \\
\text { in the } \mathrm{EU}^{\mathrm{b}}\end{array}$} & \multirow[b]{2}{*}{$\underset{(\min )}{\mathrm{tR}}$} & \multirow[b]{2}{*}{ Polarity } & \multicolumn{2}{|c|}{ Quantification } & \multicolumn{2}{|c|}{ Confirmation } & \multirow[b]{2}{*}{$\begin{array}{c}\text { Fragmentor } \\
\text { Voltage } \\
\text { (V) }\end{array}$} \\
\hline & & & & & & $\begin{array}{c}\text { MRM } \\
\text { Transition } \\
(\mathrm{m} / \mathrm{z})\end{array}$ & $\begin{array}{c}\mathrm{CE} \\
(\mathrm{eV})\end{array}$ & $\begin{array}{c}\text { MRM } \\
\text { transition } \\
(m / z)\end{array}$ & $\begin{array}{l}\mathrm{CE} \\
(\mathrm{eV})\end{array}$ & \\
\hline 27 & Naproxen & $\begin{array}{l}\text { PhACs, } \\
\text { NSAID }\end{array}$ & Approved & 7.60 & Positive & $231.1 \rightarrow 185.0$ & 10 & $231.1 \rightarrow 169.9$ & 13 & 120 \\
\hline 28 & Cortiscosterone & PhACs, GC & Approved & 7.91 & Positive & $389.1 \rightarrow 329.0$ & 13 & $389.1 \rightarrow 371.0$ & 13 & 80 \\
\hline 29 & Fenbendazole & PhACs, AH & Approved & 8.11 & Positive & $300.1 \rightarrow 268.1$ & 20 & $300.1 \rightarrow 159.0$ & 36 & 156 \\
\hline 30 & Flunixin & $\begin{array}{l}\text { PhACs, } \\
\text { NSAID }\end{array}$ & Approved & 8.11 & Positive & $297.1 \rightarrow 279.1$ & 24 & $297.1 \rightarrow 264.1$ & 32 & 141 \\
\hline 31 & Diclofenac & $\begin{array}{l}\text { PhACs, } \\
\text { NSAID }\end{array}$ & Approved & 8.75 & Positive & $296.0 \rightarrow 215.1$ & 16 & $296.0 \rightarrow 214.1$ & 48 & 103 \\
\hline 32 & Imipenem & PhACs, AB & Approved & 8.75 & Positive & $300.0 \rightarrow 125.9$ & 15 & $300.0 \rightarrow 98.0$ & 15 & 50 \\
\hline 33 & Mefenamic acid & $\begin{array}{l}\text { PhACs, } \\
\text { NSAID }\end{array}$ & Approved & 9.52 & Positive & $242.1 \rightarrow 209.1$ & 28 & $242.1 \rightarrow 180.1$ & 44 & 108 \\
\hline 34 & Tolfenamic acid & $\begin{array}{l}\text { PhACs, } \\
\text { NSAID }\end{array}$ & Approved & 9.78 & Negative & $260.0 \rightarrow 216.1$ & 8 & $260.0 \rightarrow 35.1$ & 20 & 108 \\
\hline 35 & Eprinomectin & PhACs, AB & Approved & 10.83 & Positive & $878.5 \rightarrow 186.0$ & 15 & $878.5 \rightarrow 154.0$ & 45 & 160 \\
\hline 36 & Moxidectin & PhACs, AH & Approved & 11.25 & Positive & $641.4 \rightarrow 529.2$ & 5 & $641.4 \rightarrow 499.2$ & 5 & 100 \\
\hline 37 & Warfarin & ARs & Not approved & 7.87 & Negative & $307.1 \rightarrow 161.1$ & 20 & $307.1 \rightarrow 250.1$ & 20 & 140 \\
\hline 38 & Coumatetralyl & ARs & Not approved & 8.28 & Negative & $291.1 \rightarrow 141.0$ & 30 & $291.1 \rightarrow 247.0$ & 20 & 140 \\
\hline 39 & Bromadiolone & ARs & Approved & 9.74 & Negative & $525.3 \rightarrow 250.0$ & 40 & $527.3 \rightarrow 250.0$ & 40 & 200 \\
\hline 40 & Difenacoum & ARs & Not approved & 10.27 & Negative & $443.2 \rightarrow 135.0$ & 40 & $443.2 \rightarrow 293.0$ & 35 & 200 \\
\hline 41 & Flocoumafen & ARs & Not approved & 10.36 & Negative & $541.3 \rightarrow 382.0$ & 25 & $541.3 \rightarrow 161.0$ & 40 & 230 \\
\hline 42 & Brodifacoum & ARs & Not approved & 10.67 & Negative & $521.3 \rightarrow 79.0$ & 50 & $523.3 \rightarrow 135.0$ & 45 & 220 \\
\hline \multirow[t]{7}{*}{43} & Difethialone & ARs & Not approved & 10.80 & Negative & $537.3 \rightarrow 79.0$ & 50 & $537.3 \rightarrow 151.0$ & 45 & 220 \\
\hline & Cyromazine-d4 & P-IS & - & 1.58 & Positive & $171.0 \rightarrow 86.0$ & 15 & $171.0 \rightarrow 129.0$ & 15 & 100 \\
\hline & Carbendazim-d3 & P-IS & - & 3.45 & Positive & $195.1 \rightarrow 160.1$ & 15 & $195.1 \rightarrow 131.9$ & 30 & 100 \\
\hline & Pirimicarb-d6 & P-IS & - & 5.12 & Positive & $245.2 \rightarrow 78.2$ & 5 & $245.2 \rightarrow 185.1$ & 15 & 70 \\
\hline & Atrazine-d5 & P-IS & - & 6.66 & Positive & $221.2 \rightarrow 179.0$ & 15 & $221.2 \rightarrow 101.0$ & 30 & 90 \\
\hline & Linuron-d3 & P-IS & - & 7.45 & Positive & $255.1 \rightarrow 159.8$ & 15 & $255.1 \rightarrow 185.0$ & 15 & 100 \\
\hline & Coumachlor & P-IS & - & 8.52 & Negative & $341.1 \rightarrow 161.0$ & 15 & $341.1 \rightarrow 284.0$ & 15 & 120 \\
\hline
\end{tabular}

CE: Collision Energy; tR: Retention time. ${ }^{a} \mathrm{PhACs}-$ pharmaceuticals active compound, ARs-anticoagulant rodenticides, AHanthelminthic, AB - antibiotic, NSAID—nonsteroidal anti-inflamatory drug, GC - glucocorticoid, P-IS—Procedural Internal Standard ${ }^{\mathrm{b}}$ For human and veterinary drugs, the marketing status in Spain is specified, as shown in the Cima and Cimavet search engine of the Spanish agency for drugs and health products (https: / cima.aemps.es/cima/publico/home.html accessed on 8 March 2021; https:/ / cimavet.aemps. es/cimavet/publico/home.html accessed on 8 March 2021). For rodenticides, the legal status reflecting the EU Pesticide Database was considered (https: / / ec.europa.eu/food/plant/pesticides/eu-pesticidesdatabase/public/? event=activesubstance.selection\&language=EN accessed on 8 March 2021), which is valid for the entire EU.-Not applicable.

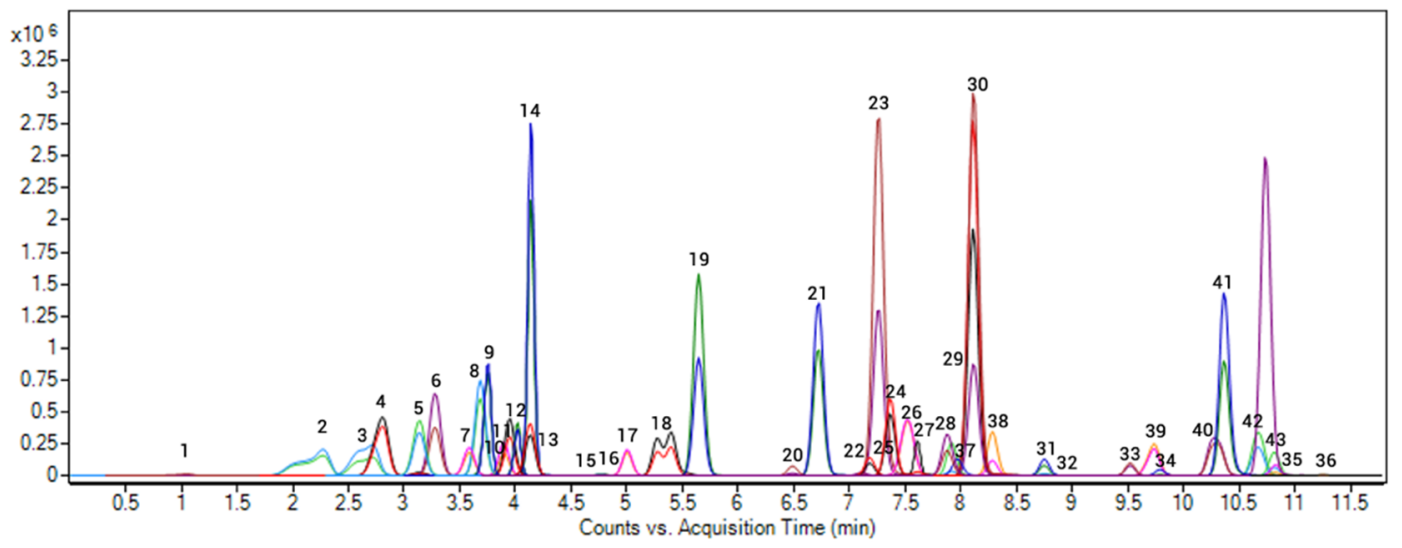

Figure 1. LC-MS/MS chromatograms of a blank soil sample spiked with the anticoagulant rodenticides (ARs) and the pharmaceutical active compounds (PhACs) at $50 \mathrm{ng} \mathrm{g}^{-1}$. 


\subsection{Matrix Effect Study}

Soil is an extremely complex matrix whose components can suppress or enhance the response of the target analytes in the mass spectrometer and can therefore condition the integrity of the analysis. Bearing this in mind, a study of the matrix effect was performed. The matrix effect (ME) was evaluated comparing the slopes of calibration curves in the solvent $\left(\mathrm{S}_{\mathrm{S}}\right)$ and in the matrix $\left(\mathrm{S}_{\mathrm{m}}\right)$, which was extracted using the procedure described in Section 2.4, according to the equation:

$$
\operatorname{ME}(\%)=\left(\mathrm{S}_{\mathrm{m}} / \mathrm{S}_{\mathrm{S}}\right) \times 100
$$

Hence, the effect of the matrix components on the signal is qualified as the percentage of enhancement or suppression, whether the ME values are above or below $100 \%$, respectively. No significant matrix effects were considered when ME was between 80-120\% [61].

The calibration curves covered the range of 3.125 to $50 \mathrm{ng} \mathrm{g}^{-1}$ and were prepared either in soil matrix or ACN 2.5\%FA, both diluted with ultrapure water $(1: 1, v / v)$. All curves were prepared in triplicate and adjusted to a linearity equation $(y=a x+b)$. Figure 2 shows ME mean values and SD together with the tolerance interval in which no matrix effect is considered (in grey). As can be seen in the graph, the majority of the analytes did not present a significant matrix effect. However, moxidectin, sulfanilamide, and sulfapyridine showed strong, medium, and slightly significant signal suppression, respectively, and only tolfenamic acid showed strong signal enhancement. Although cloxacillin and imipenem are in the tolerance range of ME\%, they presented a variable value with RSD $\%$ over $20 \%$. Consequently, matrix-matched calibration was used for quantification in the subsequent experiments.

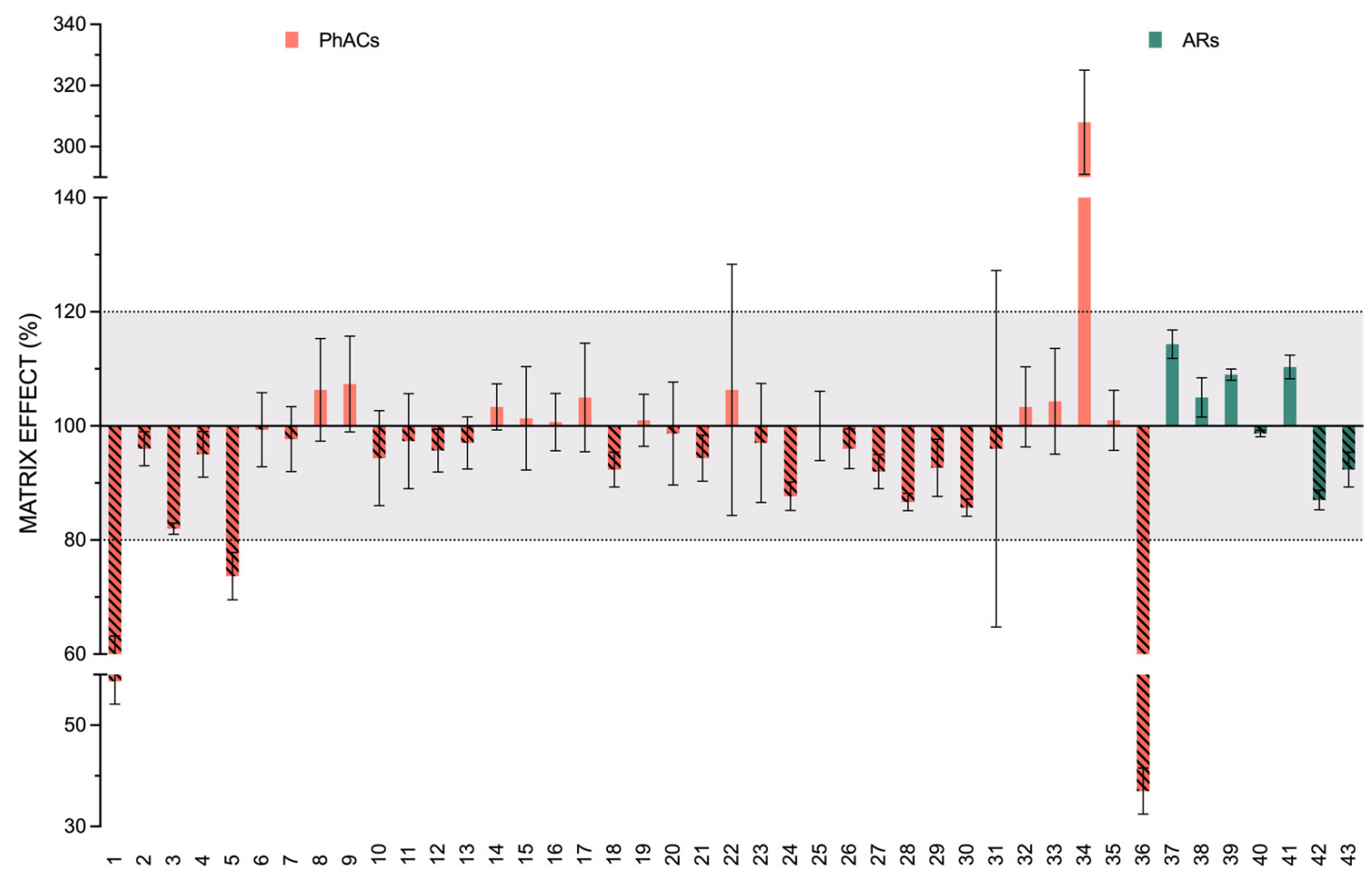

Figure 2. Matrix effect of the ARs and PhACs in the soil used for the validation process. Bars represent the mean recoveries and the SD of the 43 analytes. PhACs (orange) and ARs (green) are presented according to their number in Table 1. The suppression has been indicated with an oblique dashed pattern. 


\subsection{In House Validation Studies}

The proposed extraction method was validated following the agreements stated in the "In house validation parameters" section.

Linearity response was satisfactory in the studied range for each compound, with $\mathrm{R}^{2}$ values higher than 0.99 and $p$-values over 0.05 after Mandel test application (Table 2). All ARs and the majority of the PhACs were satisfactorily extracted in terms of accuracy and precision from their LOQ to the highest concentration tested, with recoveries between $70-120 \%$ and RSD values below $20 \%$, respectively. However, cloxacillin and tolfenamic acid showed recoveries above $120 \%$ for some of the concentration levels. Similarly, albendazole, dexamethasone, flunixin, oxfendazole, penicillin V, sulfacetamide, sulfametoxipiridacine, sulfamonomethoxine, sulfanilamide and sulfapyridine were recovered below $70 \%$ at some of these levels. However, all of these compounds were extracted with high reproducibility (RSD $<20 \%$ ) in the range of $60-130 \%$, which is contemplated in the SANTE guidelines for routine analysis [58]. On the other hand, other PhACs showed high variability (RSD > 20\%) at $5 \mathrm{ng} \mathrm{g}^{-1}$ or below but were recovered between $70-120 \%$ which is also taken into account in these guidelines for concentration below $10 \mathrm{ng} \mathrm{g}^{-1}$ of residues in soils. The results of the recovery experiments are summarized in Table 3 .

Table 2. Linear studies and threshold limits of the ARs and PhACs.

\begin{tabular}{|c|c|c|c|c|c|c|c|}
\hline $\mathbf{N}^{\circ}$ & Compound & Group & $\begin{array}{l}\text { Linear Range } \\
\left(\mathrm{ng} \mathrm{g}^{-1}\right)\end{array}$ & $\mathbf{R}^{2}$ & $\begin{array}{c}p \text {-Value } \\
\text { (Mandel Test) }^{a}\end{array}$ & $\begin{array}{c}\text { LOD } \\
\left(\mathrm{ng} \mathrm{g}^{-1}\right)\end{array}$ & $\begin{array}{c}\mathrm{LOQ} \\
\left(\mathrm{ng} \mathrm{g}^{-1}\right)\end{array}$ \\
\hline 1 & Sulfanilamide & PhACs & $1.56-25$ & 0.9989 & 0.1611 & 1.560 & 2.5 \\
\hline 2 & Sulfacetamide & PhACs & $0.195-50$ & 0.9995 & 0.5511 & 0.195 & 0.5 \\
\hline 3 & Metronidazole & PhACs & 0.195-25 & 0.9977 & 0.4488 & 0.195 & 0.5 \\
\hline 4 & Sulfadiacine & PhACs & $0.195-50$ & 0.9996 & 0.4122 & 0.195 & 0.5 \\
\hline 5 & Sulfapyridine & PhACs & $0.39-50$ & 0.999 & 0.2055 & 0.390 & 0.5 \\
\hline 6 & Sulfameracine & PhACs & $0.39-25$ & 0.9986 & 0.9810 & 0.390 & 1.0 \\
\hline 7 & Sulfametizole & PhACs & $1.56-25$ & 0.9945 & 0.2324 & 1.560 & 10.0 \\
\hline 8 & Sulfametacine & PhACs & $0.39-25$ & 0.9972 & 0.1826 & 0.390 & 0.5 \\
\hline 9 & Sulfametoxipiridacine & PhACs & $0.39-25$ & 0.9974 & 0.9264 & 0.390 & 0.5 \\
\hline 10 & Sulfachloropiridacine & PhACs & $0.39-25$ & 0.9931 & 0.4149 & 0.390 & 2.5 \\
\hline 11 & Sulfametoxazole & PhACs & $0.195-25$ & 0.9989 & 0.1782 & 0.195 & 2.5 \\
\hline 12 & Sulfamonomethoxine & PhACs & $0.78-50$ & 0.9956 & 0.0696 & 0.780 & 1.0 \\
\hline 13 & Sulfadoxine & PhACs & $0.195-25$ & 0.9996 & 0.3357 & 0.195 & 0.5 \\
\hline 14 & Sulfisoxazole & PhACs & $0.78-25$ & 0.9975 & 0.8231 & 0.780 & 1.0 \\
\hline 15 & Chloramphenicol & PhACs & $6.25-50$ & 0.9900 & 0.8866 & 6.250 & 20.0 \\
\hline 16 & Sulfadimetoxine & PhACs & $0.195-50$ & 0.9998 & 0.1956 & 0.195 & 0.5 \\
\hline 17 & Sulfaquinoxaline & PhACs & $0.78-50$ & 0.9987 & 0.0582 & 0.780 & 1.0 \\
\hline 18 & $\begin{array}{l}\text { Cefuroxime axetil } \\
\text { (two isomers) }\end{array}$ & PhACs & $0.39-50$ & 0.9929 & 0.3722 & 0.390 & 1.0 \\
\hline 19 & Oxfendazole & PhACs & $0.39-50$ & 0.9998 & 0.3931 & 0.390 & 0.5 \\
\hline 20 & Penicillin V & PhACs & $1.56-25$ & 0.9987 & 0.8550 & 1.560 & 2.5 \\
\hline
\end{tabular}


Table 2. Cont.

\begin{tabular}{|c|c|c|c|c|c|c|c|}
\hline $\mathbf{N}^{\circ}$ & Compound & Group & $\begin{array}{l}\text { Linear Range } \\
\left(\mathrm{ng} \mathrm{g}^{-1}\right)\end{array}$ & $\mathbf{R}^{2}$ & $\begin{array}{c}p \text {-Value } \\
\text { (Mandel Test) }^{a}\end{array}$ & $\begin{array}{c}\text { LOD } \\
\left(\mathrm{ng} \mathrm{g}^{-1}\right)\end{array}$ & $\begin{array}{c}\mathrm{LOQ} \\
\left(\mathrm{ng} \mathrm{g}^{-1}\right)\end{array}$ \\
\hline 21 & Mebendazole & PhACs & $0.195-50$ & 0.9997 & 0.1391 & 0.195 & 0.5 \\
\hline 22 & Cloxacillin & PhACs & $1.56-50$ & 0.9904 & 0.1094 & 1.560 & 2.5 \\
\hline 23 & Dexamethasone & PhACs & $1.56-50$ & 0.9974 & 0.0826 & 1.560 & 5.0 \\
\hline 24 & Albendazole & PhACs & $0.097-25$ & 0.9969 & 0.6387 & 0.097 & 0.5 \\
\hline 25 & Ketoprofen & PhACs & $0.39-50$ & 0.9985 & 0.7022 & 0.390 & 0.5 \\
\hline 26 & Josamycin & PhACs & $0.39-25$ & 0.9994 & 0.4666 & 0.390 & 1.0 \\
\hline 27 & Naproxen & PhACs & $3.125-50$ & 0.9918 & 0.3095 & 3.125 & 20.0 \\
\hline 28 & Cortiscosterone & PhACs & $1.56-25$ & 0.9974 & 0.6711 & 1.560 & 5.0 \\
\hline 29 & Fenbendazole & PhACs & $0.048-25$ & 0.9979 & 0.5551 & 0.048 & 0.5 \\
\hline 30 & Flunixin & PhACs & $0.097-25$ & 0.9997 & 0.4675 & 0.097 & 0.5 \\
\hline 31 & Imipenem & PhACs & $6.25-50$ & 0.9996 & 0.2499 & 6.250 & 50.0 \\
\hline 32 & Diclofenac & PhACs & $0.097-50$ & 0.9938 & 0.7354 & 0.097 & 2.5 \\
\hline 33 & Mefenamic acid & PhACs & $0.78-25$ & 0.9967 & 0.1425 & 0.780 & 10.0 \\
\hline 34 & Tolfenamic acid & PhACs & $6.25-50$ & 0.9971 & 0.4907 & 6.250 & 10.0 \\
\hline 35 & Eprinomectin & PhACs & $0.78-25$ & 0.9974 & 0.2500 & 0.780 & 2.5 \\
\hline 36 & Moxidectin & PhACs & $1.56-25$ & 0.9972 & 0.1269 & 1.560 & 20.0 \\
\hline 37 & Warfarin & ARs & $0.39-25$ & 0.9941 & 0.1400 & 0.390 & 1.0 \\
\hline 38 & Coumatetralyl & ARs & $0.195-25$ & 0.9977 & 0.1055 & 0.195 & 2.5 \\
\hline 39 & Bromadiolone & ARs & $0.195-25$ & 0.9991 & 0.1691 & 0.195 & 1.0 \\
\hline 40 & Difenacoum & ARs & $0.097-50$ & 0.9943 & 0.2221 & 0.097 & 1.0 \\
\hline 41 & Flocoumafen & ARs & $0.024-50$ & 0.9983 & 0.2167 & 0.024 & 1.0 \\
\hline 42 & Brodifacoum & ARs & $0.097-50$ & 0.9997 & 0.5200 & 0.195 & 1.0 \\
\hline 43 & Difethialone & ARs & $3.125-50$ & 0.9946 & 0.0797 & 3.125 & 20.0 \\
\hline
\end{tabular}

a According to Mandel's test, the null hypothesis (H0) would indicate that the linear model is adequate to describe the calibration data. Since $p$-value $>0.05$ in the range indicated in the table, we accept the $\mathrm{H} 0$ and would conclude that the linear model is adequate or reasonable to model the calibration data within this range.

Table 3. Recoveries (Rec) and relative standard deviation (RSD).

\begin{tabular}{|c|c|c|c|c|c|c|c|c|c|c|c|c|c|c|c|c|}
\hline \multirow[b]{2}{*}{$\mathbf{N}^{\circ}$. } & \multirow{2}{*}{ Compound } & \multirow{2}{*}{ Group } & \multicolumn{2}{|c|}{$0.5\left(\mathrm{ng} \mathrm{g}^{-1}\right)$} & \multicolumn{2}{|c|}{$1.0\left(\mathrm{ng} \mathrm{g}^{-1}\right)$} & \multicolumn{2}{|c|}{$2.5\left(\mathrm{ng} \mathrm{g}^{-1}\right)$} & \multicolumn{2}{|c|}{$5\left(\operatorname{ng~g~}^{-1}\right)$} & \multicolumn{2}{|c|}{$\begin{array}{c}10.0 \\
\left(\mathrm{ng} \mathrm{g}^{-1}\right)\end{array}$} & \multicolumn{2}{|c|}{$\begin{array}{c}20.0 \\
\left(\mathrm{ng} \mathrm{g}^{-1}\right)\end{array}$} & \multicolumn{2}{|c|}{$\begin{array}{c}50.0 \\
\left(\mathrm{ng} \mathrm{g}^{-1}\right)\end{array}$} \\
\hline & & & $\begin{array}{l}\operatorname{Rec} \\
(\%)\end{array}$ & $\begin{array}{l}\text { RSD } \\
(\%)\end{array}$ & $\begin{array}{l}\operatorname{Rec} \\
(\%)\end{array}$ & $\begin{array}{l}\text { RSD } \\
(\%)\end{array}$ & $\begin{array}{l}\operatorname{Rec} \\
(\%)\end{array}$ & $\begin{array}{l}\text { RSD } \\
(\%)\end{array}$ & $\begin{array}{l}\operatorname{Rec} \\
(\%)\end{array}$ & $\begin{array}{l}\text { RSD } \\
(\%)\end{array}$ & $\begin{array}{l}\operatorname{Rec} \\
(\%)\end{array}$ & $\begin{array}{l}\text { RSD } \\
(\%)\end{array}$ & $\begin{array}{l}\text { Rec } \\
(\%)\end{array}$ & $\begin{array}{l}\text { RSD } \\
(\%)\end{array}$ & $\begin{array}{l}\text { Rec } \\
(\%)\end{array}$ & $\begin{array}{l}\text { RSD } \\
(\%)\end{array}$ \\
\hline 1 & Sulfanilamide & PhACs & $\mathrm{N} / \mathrm{A}$ & $\mathrm{N} / \mathrm{A}$ & $\mathrm{N} / \mathrm{A}$ & N/A & 112.1 & 7.9 & 90.7 & 24.2 & 91.3 & 17.9 & 79.9 & 9.0 & 63.3 & 12.8 \\
\hline 2 & Sulfacetamide & PhACs & 83.3 & 15.1 & 63.2 & 10.3 & 59.8 & 8.1 & 78.0 & 16.5 & 58.6 & 5.4 & 62.8 & 5.9 & 75.5 & 3.7 \\
\hline 3 & Metronidazole & PhACs & 75.3 & 16.8 & 86.5 & 26.9 & 87.5 & 7.3 & 102.5 & 13.1 & 94.4 & 8.0 & 97.7 & 5.5 & 92.7 & 1.6 \\
\hline 4 & Sulfadiacine & PhACs & 88.1 & 13.8 & 76.0 & 8.2 & 74.4 & 5.0 & 83.8 & 13.7 & 75.1 & 5.1 & 78.1 & 6.9 & 77.6 & 2.1 \\
\hline 5 & Sulfapyridine & PhACs & 111.0 & 18.9 & 78.2 & 16.1 & 72.2 & 5.2 & 79.2 & 21.8 & 75.2 & 9.7 & 68.7 & 7.7 & 69.7 & 3.2 \\
\hline 6 & Sulfameracine & PhACs & N/A & N/A & 91.6 & 19.4 & 81.3 & 2.7 & 85.7 & 14.7 & 78.2 & 5.1 & 80.5 & 9.2 & 78.9 & 3.7 \\
\hline 7 & Sulfametizole & PhACs & $\mathrm{N} / \mathrm{A}$ & N/A & N/A & N/A & $\mathrm{N} / \mathrm{A}$ & N/A & $\mathrm{N} / \mathrm{A}$ & N/A & $\mathrm{N} / \mathrm{A}$ & 9.8 & 71.2 & 13.4 & 68.6 & 3.8 \\
\hline 8 & Sulfametacine & PhACs & 106.8 & 9.9 & 84.0 & 17.8 & 78.5 & 11.4 & 83.9 & 18.8 & 78.9 & 3.2 & 83.9 & 7.7 & 85.4 & 1.5 \\
\hline 9 & Sulfametoxipiridacine & PhACs & 84.1 & 10.5 & 72.0 & 21.6 & 62.5 & 7.8 & 82.7 & 17.9 & 75.5 & 6.1 & 74.2 & 5.8 & 75.0 & 2.6 \\
\hline
\end{tabular}


Table 3. Cont.

\begin{tabular}{|c|c|c|c|c|c|c|c|c|c|c|c|c|c|c|c|c|}
\hline \multirow[b]{2}{*}{$\mathbf{N}^{\circ}$. } & \multirow[b]{2}{*}{ Compound } & \multirow[b]{2}{*}{ Group } & \multicolumn{2}{|c|}{$0.5\left(\mathrm{ng} \mathrm{g}^{-1}\right)$} & \multicolumn{2}{|c|}{$1.0\left(\mathrm{ng} \mathrm{g}^{-1}\right)$} & \multicolumn{2}{|c|}{$2.5\left(\mathrm{ng} \mathrm{g}^{-1}\right)$} & \multicolumn{2}{|c|}{$5\left(\mathrm{ng} \mathrm{g}^{-1}\right)$} & \multicolumn{2}{|c|}{$\begin{array}{c}10.0 \\
\left(\mathrm{ng} \mathrm{g}^{-1}\right)\end{array}$} & \multicolumn{2}{|c|}{$\begin{array}{c}20.0 \\
\left(\mathrm{ng} \mathrm{g}^{-1}\right)\end{array}$} & \multicolumn{2}{|c|}{$\begin{array}{c}50.0 \\
\left(\mathrm{ng} \mathrm{g}^{-1}\right)\end{array}$} \\
\hline & & & $\begin{array}{l}\operatorname{Rec} \\
(\%)\end{array}$ & $\begin{array}{l}\text { RSD } \\
(\%)\end{array}$ & $\begin{array}{l}\text { Rec } \\
(\%)\end{array}$ & $\begin{array}{l}\text { RSD } \\
(\%)\end{array}$ & $\begin{array}{l}\text { Rec } \\
(\%)\end{array}$ & $\begin{array}{l}\text { RSD } \\
(\%)\end{array}$ & $\begin{array}{l}\text { Rec } \\
(\%)\end{array}$ & & $\begin{array}{l}\operatorname{Rec} \\
(\%)\end{array}$ & $\begin{array}{l}\text { RSD } \\
(\%)\end{array}$ & $\begin{array}{l}\operatorname{Rec} \\
(\%)\end{array}$ & $\begin{array}{l}\text { RSD } \\
(\%)\end{array}$ & $\begin{array}{l}\text { Rec } \\
(\%)\end{array}$ & $\begin{array}{l}\text { RSD } \\
(\%)\end{array}$ \\
\hline 10 & ulfac & $\mathrm{AACs}$ & $\mathrm{N} / \mathrm{A}$ & $\mathrm{N} / \mathrm{A}$ & $\mathrm{N} / \mathrm{A}$ & $\mathrm{N} / \mathrm{A}$ & 81.6 & 16 & 85.7 & 22.7 & 84.3 & 6. & 87.7 & 6.7 & 89.6 & 2.8 \\
\hline 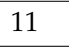 & & $\mathrm{ACs}$ & $\mathrm{J} / \mathrm{A}$ & N/A & N/A & N/A & 89.3 & 13.1 & 96.4 & 16.7 & 93.3 & 7.2 & 101.2 & 2.4 & 103.2 & 3.0 \\
\hline 12 & ulfamonomethe & $\mathrm{ACs}$ & $\mathrm{N} / \mathrm{A}$ & $\mathrm{N} / \mathrm{A}$ & 75.2 & 10.7 & 66.6 & 7.6 & 80.2 & 30.7 & 75.8 & 4.4 & 80.3 & 9.1 & 80.6 & 6.1 \\
\hline 13 & Sulfadoxine & $\mathrm{nACs}$ & 96.5 & 9.7 & 86.1 & 6.7 & 85.2 & 4.7 & 96.8 & 16.0 & 90.0 & 6.7 & 94.0 & 5.9 & 89.9 & 1.4 \\
\hline 14 & Sulfis & $\mathrm{AACs}$ & N/A & N/A & 89.8 & 13.9 & 77.4 & 15.7 & 82.8 & 18.9 & 71.3 & 10.6 & 80.1 & 7.0 & 80.8 & 3.5 \\
\hline 15 & Chloramphenicol & $\mathrm{hACs}$ & N/A & N/A & N/A & N/A & N/A & $\mathrm{N} / \mathrm{A}$ & N/A & $\mathrm{N} / \mathrm{A}$ & N/A & $\mathrm{N} / \mathrm{A}$ & 117.0 & 11.0 & 117.8 & 9.0 \\
\hline 16 & Sulfadin & $\mathrm{AACs}$ & 85.7 & 10.3 & 86.7 & 7.4 & 84.8 & 4.0 & 91.9 & 15.6 & 86.2 & 6.0 & 90.9 & 5.7 & 88.2 & 1.3 \\
\hline 17 & noxaline & $\mathrm{AACs}$ & $\mathrm{N} / \mathrm{A}$ & $\mathrm{N} / \mathrm{A}$ & 111.1 & 8.8 & 82.9 & 7.5 & 84.7 & 16.6 & 74.1 & 5.7 & 77.0 & 7.4 & 78.9 & 2.1 \\
\hline 18 & & $\mathrm{ACs}$ & $\mathrm{N} / \mathrm{A}$ & $\mathrm{N} / \mathrm{A}$ & 83.4 & 18.2 & 96.1 & 6.8 & 117.2 & 11.5 & 109.5 & 6.7 & 15.5 & 5.3 & 104.3 & 0.7 \\
\hline 19 & $0 \times$ & Cs & 115.1 & 13.1 & 83.4 & 9.8 & 65.2 & 2.9 & 02.0 & 13.8 & 69.9 & . & 66.2 & 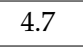 & 63.4 & 0.4 \\
\hline 20 & $\ln V$ & Cs & $\mathrm{N} / \mathrm{A}$ & N/A & N/A & $\mathrm{N} / \mathrm{A}$ & 66.5 & 17.6 & 69.7 & 26.7 & 63.0 & 18.2 & 65.9 & 12.8 & 73.2 & 9.9 \\
\hline 21 & $\mathrm{ebc}$ & $\mathrm{ACs}$ & 92.4 & 15.4 & 79.8 & 13.4 & 75.1 & 4.6 & 96.0 & 18.0 & 80.7 & 5.6 & 80.7 & 64 & 79.3 & 1.5 \\
\hline 22 & Cloxacillin & PhACs & $\mathrm{N} / \mathrm{A}$ & $\mathrm{N} / \mathrm{A}$ & N/A & $\mathrm{N} / \mathrm{A}$ & 76.1 & 15.4 & 122.3 & 18.6 & 98.7 & 9.2 & 101.8 & 9.7 & 126.0 & 11.7 \\
\hline 23 & examethasone & PhACs & N/A & N/A & N/A & N/A & N/A & N/A & 71.1 & 17.6 & 68.0 & 9.1 & 75.4 & 6.2 & 69.9 & 3.6 \\
\hline 24 & lbendazole & PhACs & 76.3 & 9.0 & 76.3 & 8.2 & 69.5 & 3.8 & 99.5 & 16.5 & 82.9 & 6.3 & 76.2 & 5.9 & 75.8 & 1.1 \\
\hline 25 & fen & $\mathrm{ACs}$ & 103.5 & 18.3 & 99.8 & 13.8 & 76.6 & 6.7 & 93.4 & 20.7 & 92.1 & 6.8 & 89.6 & 4.9 & 87.2 & 3.2 \\
\hline 26 & amycin & s & N/A & N/A & 1 & 1 & 7 & 1 & 0 & 20.2 & 70.3 & & 8 & & .1 & 5.6 \\
\hline 27 & 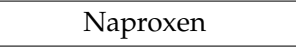 & Cs & N/A & N/A & N/A & N/A & N/A & N/A & N/A & N/A & N/A & N/A & 86.9 & 18.1 & 94.2 & 5.2 \\
\hline 28 & Cortiscosterone & PhACs & N/A & N/A & N/A & N/A & N/A & N/A & 112.9 & 15.4 & 93.9 & 6.3 & 101.3 & 10.8 & 99.7 & 5.4 \\
\hline 29 & Fenbendazole & PhACs & 93.9 & 12.2 & 87.1 & 8.9 & 83.0 & 6.2 & 107.0 & 14.6 & 92.2 & 5.3 & 90.6 & 6.2 & 85.3 & 1.4 \\
\hline 30 & Flunixin & PhACs & 81.0 & 11.3 & 70.2 & 17.3 & 68.6 & 4.2 & 81.9 & 17.0 & 71.8 & 4.2 & 69.8 & 4.2 & 65.0 & 2.7 \\
\hline 31 & nipenem & $\mathrm{AACs}$ & N/A & N/A & N/A & N/A & N/A & N/A & N/A & N/A & N/A & N/A & N/A & N/A & 91.7 & 17.2 \\
\hline 32 & iclofenac & PhACs & N/A & N/A & N/A & N/A & 110.3 & 17.9 & 107.1 & 28.8 & 84.4 & 17.7 & 93.9 & 8.1 & 85.1 & 2.1 \\
\hline 33 & Mefenamic acid & PhACs & $\mathrm{N} / \mathrm{A}$ & $\mathrm{N} / \mathrm{A}$ & $\mathrm{N} / \mathrm{A}$ & $\mathrm{N} / \mathrm{A}$ & $\mathrm{N} / \mathrm{A}$ & $\mathrm{N} / \mathrm{A}$ & $\mathrm{N} / \mathrm{A}$ & N/A & 82.7 & 14.3 & 83.1 & 17.2 & 82.5 & 5.9 \\
\hline 34 & Tolfenamic acid & PhACs & N/A & N/A & N/A & N/A & N/A & N/A & N/A & N/A & 121.5 & 15.4 & 121.2 & 7.8 & 111.5 & 10.2 \\
\hline 35 & rinomectin & PhACs & $\mathrm{N} / \mathrm{A}$ & $\mathrm{N} / \mathrm{A}$ & $\mathrm{N} / \mathrm{A}$ & $\mathrm{N} / \mathrm{A}$ & 102.1 & 12.7 & 104.0 & 15.4 & 98.3 & 11.8 & 92.1 & 9.5 & 84.8 & 2.6 \\
\hline 36 & Moxidectin & PhACs & N/A & N/A & N/A & N/A & N/A & N/A & N/A & N/A & N/A & N/A & 95.0 & 14.9 & 96.3 & 9.6 \\
\hline 37 & Warfarin & ARs & $\mathrm{N} / \mathrm{A}$ & $\mathrm{N} / \mathrm{A}$ & 81.2 & 9.2 & 103.8 & 4.6 & 106.0 & 14.7 & 113.5 & 6.5 & 105.5 & 4.9 & 85.8 & 5.0 \\
\hline 38 & Coumatetralyl & ARs & N/A & N/A & N/A & N/A & 104.6 & 13.5 & 106.5 & 12.8 & 107.3 & 13.0 & 99.3 & 3.3 & 87.6 & 5.9 \\
\hline 39 & Bromadiolone & ARs & N/A & N/A & 92.8 & 14.4 & 87.5 & 15.4 & 90.9 & 13.8 & 93.6 & 7.7 & 91.4 & 7.4 & 82.4 & 2.6 \\
\hline 40 & Difenacoum & ARs & N/A & N/A & 110.2 & 12.9 & 90.6 & 6.5 & 110.2 & 14.3 & 107.8 & 5.4 & 102.6 & 7.4 & 86.3 & 1.4 \\
\hline 41 & Flocoumafen & ARs & N/A & N/A & 105.0 & 13.0 & 94.1 & 16.8 & 108.1 & 11.6 & 108.9 & 8.0 & 100.8 & 5.0 & 85.1 & 1.9 \\
\hline 42 & Brodifacoum & ARs & N/A & N/A & 106.5 & 11.5 & 87.6 & 6.5 & 98.4 & 14.8 & 98.0 & 8.6 & 93.4 & 4.2 & 84.3 & 4.0 \\
\hline 43 & Difethialone & ARs & N/A & N/A & N/A & N/A & N/A & N/A & N/A & $\mathrm{N} / \mathrm{A}$ & N/A & $\mathrm{N} / \mathrm{A}$ & 113.7 & 4.9 & 95.7 & 6.2 \\
\hline
\end{tabular}

All analytes LOQs were equal to or below $20 \mathrm{ng} \mathrm{g}^{-1}$ except for imipenem with $50 \mathrm{ng} \mathrm{g}^{-1}$, which is the LOQ normally required for residues in soils according to the guidance for analytical methods for residues in soil [61]. As for the LOD, all analytes had a detection limit of $6.25 \mathrm{ng} \mathrm{g}^{-1}$ or even lower (Table 2). As mentioned above, there are very few studies that determine ARs in soil and none of them analyze difethialone residues. Moreover, the LOQ and LOD values obtained with our modified QuEChERS method are much lower than those obtained using other extraction methodologies $[27,29,31]$ except for brodifacoum, coumatetralyl, difenacoum and flocoumafen, whose LOQs are in the same range than those obtained with a $\mathrm{MeOH}$ and ammonium format extraction [28]. However, it should be noted that the LOD and LOQ in those cases were established as three and ten times the $\mathrm{S} / \mathrm{N}$ of the blank sample extract, respectively, while ours were calculated following the more restrictive criteria of the European Union SANTE guidance [58]. Furthermore, among the few QuEChERS-based extraction methods for PhACs in the literature for their 
determination in soils, our method is capable of extracting and analyzing more of these compounds. Of the compounds that coincide with those determined in the previously published methods, sulfanilamide, sulfadiazine, and sulfadimethoxine have lower LOQs in the method of Salvia et al. [35] but were determined as S/N ratio equal to 10. Similarly, Lee et al. also determined the LOQs as ten times the $\mathrm{S} / \mathrm{N}$ ratio, and obtained a LOQ for sulfamethazine that was equal to ours $\left(0.5 \mathrm{ng} \mathrm{g}^{-1}\right)$, but the one for sulfamethoxazole was lower ( 0.5 vs. $\left.2.5 \mathrm{ng} \mathrm{g}^{-1}\right)$ [33]. Finally, Ferhi et al. determined the LOQs with the results of the validation data in a more similar way to ours for diclofenac, sulfamethoxazole, and sulfamethoxazole, our values being lower in the first two cases and slightly higher but in the same range in the latter $\left(2.1 \mathrm{ng} \mathrm{g}^{-1}\right.$ vs. $\left.5 \mathrm{ng} \mathrm{g}^{-1}\right)$ [34].

In summary, the proposed QuEChERS-based method without a clean-up step was expanded from 218 [41] to 261 analytes, and now proves to be accurate and reliable for the analysis of the ARs and selected PhACs in soil samples, in addition to agricultural pesticides.

\subsection{Verifying the Method in Different Scenarios}

Once the method was validated under the above conditions, it was applied for the analysis of ARs and PhACs in two different scenarios to verify its applicability: Agricultural soils samples irrigated with regenerated water and a soil sample from an environmental forensic investigation of a suspected wildlife poisoning episode.

\subsubsection{Agricultural Soil Samples}

We decided to analyze samples from mid-range farms on the island of Gran Canaria that use regenerated water from the WWTP of the nearby city (Las Palmas de Gran Canaria, 425,000 inhabitants). In the initial analysis of the soil samples, no PhACs residues were detected in any of them, although several pesticide residues from those included in the initial method were detected in the different samples tested (data not shown, see AcostaDacal et al., 2021). In addition, thanks to the extension of the analytical scope, brodifacoum was detected in one of the soil samples, and flocoumafen in another (Figure 3, panels B and $\mathrm{C}$ ), at concentrations of 2.96 and $1.37 \mathrm{ng} \mathrm{g}^{-1}$, respectively.

Although these soil samples had been irrigated with regenerated wastewater, no $\mathrm{PhAC}$ residues were detected, so there was a possibility that the water was free of residues. In order to verify this, samples of the irrigation water from the WWTP were collected during four consecutive days. These water samples were directly analyzed in the LC-MS/MS where three authorized PhACs were detected: diclofenac, ketoprofen, and sulfamethoxazole (panel A of Figure 3). These PhACs are used for both humans and livestock. In contrast, no AR was found in the water samples. Therefore, the presence of brodifacoum and flocoumafen detected in the soil samples could have been due to a rodent-control application. It should be noted that the water analyzed, although it comes from the same treatment plant, is not the same as the water used in the irrigated plots, since it was subsequently collected. In other words, it is also possible that the water used in the irrigated plots at that time contained the rodenticides and not the PhACs. This possibility is also plausible taking into account that neither brodifacoum nor flocoumafen are EU nonauthorized pesticides as agricultural products (Table 1). 

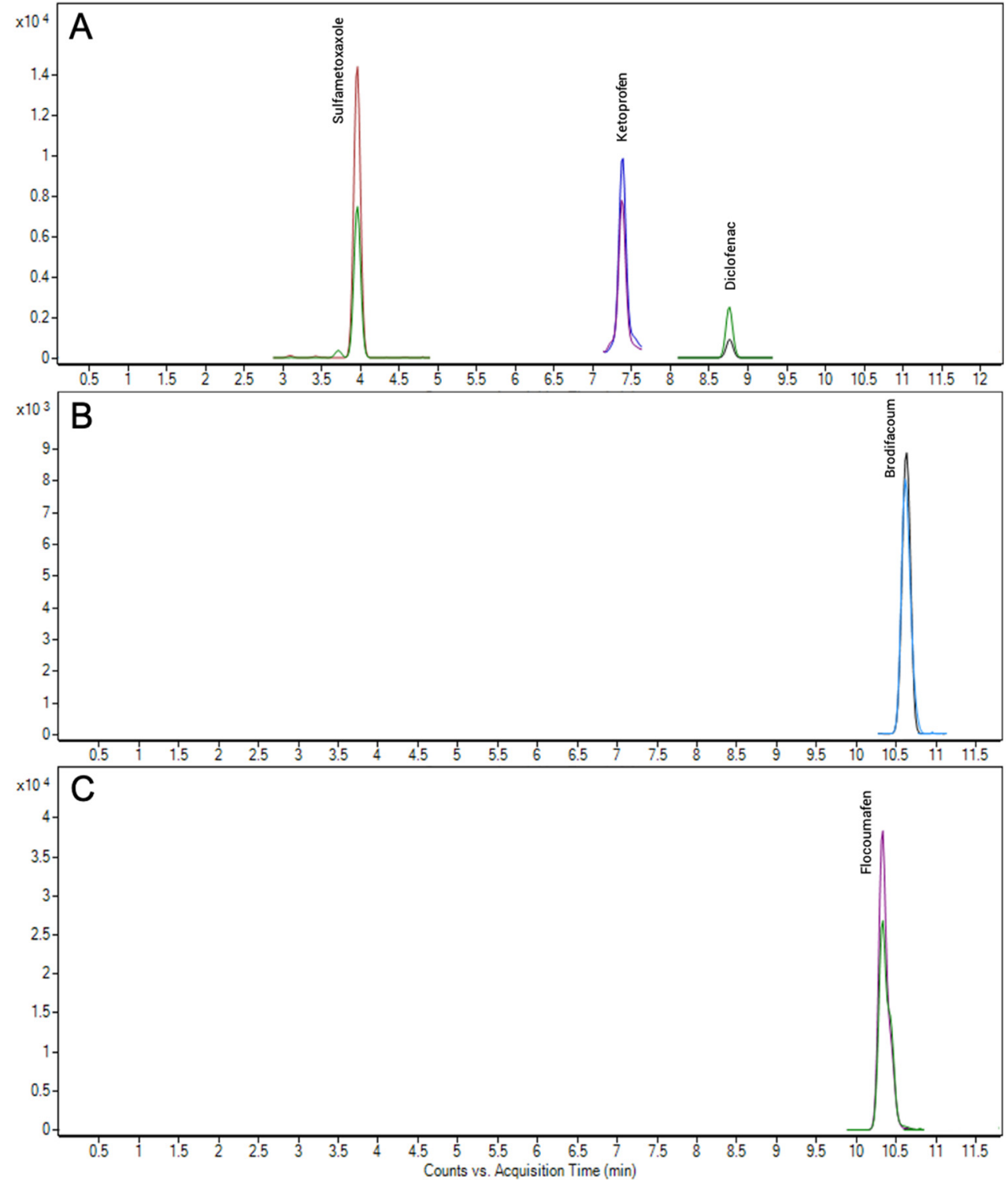

Figure 3. Chromatogram of the regenerated water (A) and the two agricultural soils with the identification of (B) brodifacoum and (C) flocoumafen.

As mentioned, ARs tend to accumulate in organic matter due to their moderate to high $\mathrm{K}_{\mathrm{OW}}$, so it is to be expected that most of them are eliminated in the active sludge treatment. This is consistent with what other authors have found, such as Gomez-Canela et al. who determined very few ARs above the detection limit in the effluents of the different treatments of the WWTPs analyzed. Nonetheless, they found flocoumafen in the effluent of the primary $\left(18.1 \mathrm{ng} \mathrm{L}^{-1}\right)$ and secondary $\left(18.1 \mathrm{ng} \mathrm{L}^{-1}\right)$ treatments from one of the WWTPs and both flocoumafen $\left(29.3 \mathrm{ng} \mathrm{L}^{-1}\right)$ and brodifacoum $\left(38.4 \mathrm{ng} \mathrm{L}^{-1}\right)$ in the effluent of the tertiary treatment of another one [8]. Therefore, we cannot discard the possibility that although we have not found them in the analyzed water, these compounds could have been present in previous days. On the other hand, the fact that the PhACs detected in water did not show up in the analyzed soil samples could have been due to the low concentrations found, which are very close to the method LOD. The mean concentrations of diclofenac, ketoprofen, and sulfamethoxazole were $1.03,0.88$, and $0.35 \mathrm{ng}$ $\mathrm{g}^{-1}$, respectively. These were either below the limit of quantification we reached with our QuEChERS-based extraction method ( $2.5 \mathrm{ng} \mathrm{g}^{-1}$ for both diclofenac and sulfamethoxazole) or slightly higher in the case of ketoprofen $\left(0.5 \mathrm{ng} \mathrm{g}^{-1}\right)$. As already mentioned, wastewater 
content and values may vary on different days even if our samples were in the same range for the period studied.

Thus, we decided to investigate whether the soil could accumulate these compounds during irrigation. First, we prepared a pool with the water samples collected during four consecutive days and concentrated it ten times with the intention of achieving a concentration much higher that the LOQ of the three compounds detected. This was performed using a vacuum concentrator RVC 2-25 CD plus (Christ, Germany) at $35^{\circ} \mathrm{C}$ and then reconstituting the sample in a volume 10 times lower of ultrapure water. After that, an irrigation simulation model was prepared with the soil used for the validation procedure. Approximately $500 \mathrm{~g}$ of soil was placed in a tray container and irrigated with $0.5 \mathrm{~L}$ of the concentrated water solution on alternate days for two weeks (Figure 4, inset). Then, the soil was left to air dry for two weeks, homogenized and extracted using the proposed method. Finally, both the concentrated water and the extract were analyzed. Diclofenac ketoprofen and sulfamethoxazole were extracted with an extraction efficiency of 93.4, 85.1, and $107.2 \%$. Therefore, the soil is capable of accumulating these compounds in irrigation if the concentration is higher. A chromatogram of the irrigated soil together with an image of the experiment can be seen in Figure 4.

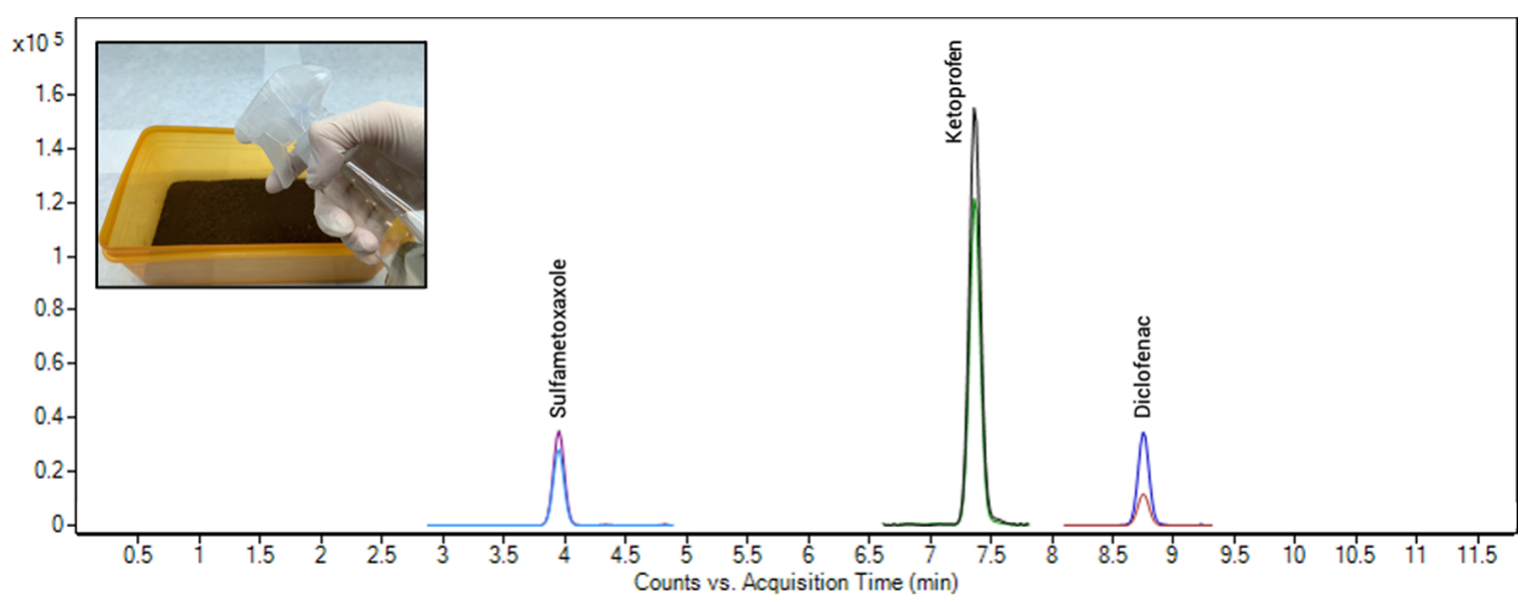

Figure 4. Chromatogram of the soil after the irrigation simulation experiment.

\subsubsection{Environmental Forensic Investigation}

Finally, we tested the validity of the method in another scenario within the context of a judicial forensic investigation. We had dealt with soil samples from a protected natural area on the island of Gran Canaria (Canary Islands, Spain) where the skeletonized remains of several protected birds (ancient corpses) were found. There were strong suspicions that a bait containing some type of poison had been maliciously placed. Therefore, several samples collected in the area were submitted, including a soil sample taken from underneath one of the corpses of a medium-sized bird of prey. This soil sample was analyzed with the method proposed in this article, and as shown in Figure 5, three ARs were identified: brodifacoum, bromadiolone and difenacoum at 223.62, 12.61 and $1.94 \mathrm{ng} \mathrm{g}^{-1}$, respectively. 


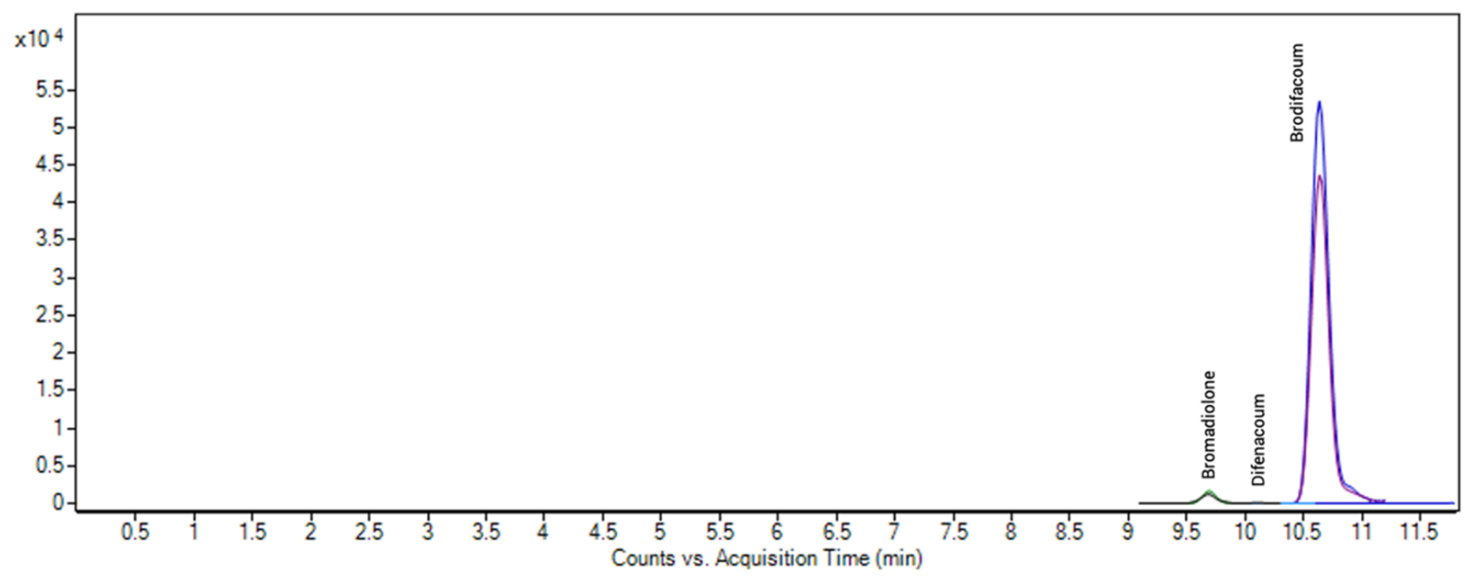

Figure 5. Chromatogram with the identification of brodifacoum, bromadiolone and difenacoum in soil underneath the remains of dead animal in the context of a forensic investigation.

\section{Conclusions}

The proposed methodology was successfully in house validated for the determination of 7 coumarin ARs and 36 PhACs in terms of linearity, trueness, and precision for all the analytes. The LODs were between 0.024 and $6.25 \mathrm{ng} \mathrm{g}^{-1}$ and LOQs in the range of $0.5-20.0 \mathrm{ng} \mathrm{g}^{-1}$, and only the imipenem presented the typically fixed LOQ for soil residues, $50 \mathrm{ng} \mathrm{g}^{-1}$. It was then applied to samples from agricultural plots irrigated with regenerated water, and brodifacoum and flocoumafen were found in two of them. It was also used in a soil sample collected from underneath wildlife carcasses in the context of an environmental forensic investigation where three ARs (brodifacoum, bromadiolone, and difenacoum) were identified.

The scope of this simple method has been extended and now allows the determination of 43 CECs in addition to the 218 pesticides in soil. Thus, it can be used for monitoring agricultural soils and for forensic purposes in soils found under wildlife carcasses. To our knowledge, this is the first time that a QuEChERS methodology is applied to ARs extraction in soil matrix.

Author Contributions: Conceptualization, A.A.-D. and O.P.L.; methodology, A.A.-D., C.R.-B. and O.P.L.; software, L.A.H.-H.; validation, A.A.-D., R.D.-D. and M.d.M.B.-S.; formal analysis, A.A.-D., C.R.-B., and M.Z.; investigation, A.A.-D., C.R.-B., and M.Z.; resources, O.P.L., and M.Z.; data curation, L.A.H.-H.; writing-original draft preparation, A.A.-D.; writing-review and editing, O.P.L., R.D.D., and M.d.M.B.-S.; visualization, O.P.L.; supervision, O.P.L., and R.D.-D.; project administration, O.P.L.; funding acquisition, O.P.L. All authors have read and agreed to the published version of the manuscript.

Funding: This research was supported by the Spanish Ministry of Education, Culture and Sports, grant number FPU16-01888, to A. Acosta-Dacal, and by the University of Las Palmas de Gran Canaria, grant number ULPGC-012-2016, to C. Rial-Berriel.

Data Availability Statement: The data presented in this study are available on request from the corresponding author. The data are not publicly available due to some of the data have been obtained from legal proceedings subject to confidentiality.

Acknowledgments: The authors would like to thank Jesús Notario from the Department of Animal Biology, Edaphology and Geology of the University of La Laguna for his help in the identification of the soil samples as clay loam soil, and Ana Macías Montes for her technical assistance in the Toxicology Laboratory of the University of Las Palmas de Gran Canaria.

Conflicts of Interest: The authors declare no conflict of interest. 


\section{References}

1. Fernandez-Alvarez, M.; Lamas, J.P.; Garcia-Chao, M.; Garcia-Jares, C.; Llompart, M.; Lores, M.; Dagnac, T. Monitoring of pesticide residues in dairy cattle farms from NW Spain. J. Environ. Monit. 2010, 12, 1864. [CrossRef] [PubMed]

2. Watt, B.E.; Proudfoot, A.T.; Bradberry, S.M.; Vale, J.A. Anticoagulant rodenticides. Toxicol. Rev. 2005, 24, 259-269. [CrossRef] [PubMed]

3. Pelfrène, A.F. Rodenticides. In Hayes' Handbook of Pesticide Toxicology; Elsevier: Amsterdam, The Netherlands, $2010 ;$ pp. $2153-2217$.

4. Murphy, M.J. Anticoagulant Rodenticides. In Veterinary Toxicology: Basic and Clinical Principles, 3rd ed.; Elsevier: Amsterdam, The Netherlands, 2018; ISBN 9780128114100.

5. Jackson, W.B.; Brooks, J.E.; Bowerman, A.M.; Kaukeinen, D.E. Anticoagulant resistance in Norway rats as found in US cities. Pest Control 1975, 43, 12-16.

6. $\quad$ Singer, D.E.; Chang, Y.; Fang, M.C.; Borowsky, L.H.; Pomernacki, N.K.; Udaltsova, N.; Go, A.S. The net clinical benefit of warfarin anticoagulation in atrial fibrillation. Ann. Intern. Med. 2009, 151, 297-305. [CrossRef] [PubMed]

7. Gómez-Canela, C.; Lacorte, S. Comprehensive characterization of anticoagulant rodenticides in sludge by liquid chromatographytandem mass spectrometry. Environ. Sci. Pollut. Res. 2016, 23, 15739-15748. [CrossRef] [PubMed]

8. Gómez-Canela, C.; Barata, C.; Lacorte, S. Occurrence, elimination, and risk of anticoagulant rodenticides and drugs during wastewater treatment. Environ. Sci. Pollut. Res. 2014, 21, 7194-7203. [CrossRef]

9. Jelić, A.; Petrović, M.; Barceló, D. Multi-residue method for trace level determination of pharmaceuticals in solid samples using pressurized liquid extraction followed by liquid chromatography/quadrupole-linear ion trap mass spectrometry. Talanta 2009, 80, 363-371. [CrossRef] [PubMed]

10. Margalida, A.; Bogliani, G.; Bowden, C.G.R.; Donázar, J.A.; Genero, F.; Gilbert, M.; Karesh, W.B.; Kock, R.; Lubroth, J.; Manteca, X.; et al. One Health approach to use of veterinary pharmaceuticals. Science (80-) 2014, 346, 1296-1298. [CrossRef]

11. Díaz-Cruz, M.S.; Barceló, D. LC-MS2 trace analysis of antimicrobials in water, sediment and soil. TrAC Trends Anal. Chem. 2005, 24, 645-657. [CrossRef]

12. Kim, K.R.; Owens, G.; Kwon, S.I.; So, K.H.; Lee, D.B.; Ok, Y.S. Occurrence and environmental fate of veterinary antibiotics in the terrestrial environment. Water. Air. Soil Pollut. 2011, 214, 163-174. [CrossRef]

13. Kaczala, F.; Blum, S.E. The Occurrence of Veterinary Pharmaceuticals in the Environment: A Review. Curr. Anal. Chem. 2015, 12, 169-182. [CrossRef]

14. Gómez-Canela, C.; Vázquez-Chica, A.; Lacorte, S. Comprehensive characterization of rodenticides in wastewater by liquid chromatography-tandem mass spectrometry. Anal. Bioanal. Chem. 2014, 406, 345-358. [CrossRef] [PubMed]

15. Gómez-Canela, C.; Barth, J.A.C.; Lacorte, S. Occurrence and fate of perfluorinated compounds in sewage sludge from Spain and Germany. Environ. Sci. Pollut. Res. 2012, 19, 4109-4119. [CrossRef]

16. Cuthbert, R.J.; Taggart, M.A.; Prakash, V.; Chakraborty, S.S.; Deori, P.; Galligan, T.; Kulkarni, M.; Ranade, S.; Saini, M.; Sharma, A.K.; et al. Avian scavengers and the threat from veterinary pharmaceuticals. Philos. Trans. R. Soc. B Biol. Sci. 2014, 369. [CrossRef] [PubMed]

17. Schaff, J.E.; Montgomery, M.A. An HPLC-HR-MS-MS Method for identification of anticoagulant rodenticides in blood *. J. Anal Toxicol. 2013, 37, 321-325. [CrossRef] [PubMed]

18. André, C.; Guyon, C.; Thomassin, M.; Barbier, A.; Richert, L.; Guillaume, Y.C. Association mechanism between a series of rodenticide and humic acid: A frontal analysis to support the biological data. J. Chromatogr. B Anal. Technol. Biomed. Life Sci. 2005, 820, 9-14. [CrossRef] [PubMed]

19. Kemper, N.; Färber, H.; Skutlarek, D.; Krieter, J. Analysis of antibiotic residues in liquid manure and leachate of dairy farms in Northern Germany. Agric. Water Manag. 2008, 95, 1288-1292. [CrossRef]

20. Pitt, W.C.; Berentsen, A.R.; Shiels, A.B.; Volker, S.F.; Eisemann, J.D.; Wegmann, A.S.; Howald, G.R. Non-target species mortality and the measurement of brodifacoum rodenticide residues after a rat (Rattus rattus) eradication on Palmyra Atoll, tropical Pacific. Biol. Conserv. 2015, 185, 36-46. [CrossRef]

21. Obimakinde, S.; Fatoki, O.; Opeolu, B.; Olatunji, O. Veterinary pharmaceuticals in aqueous systems and associated effects: An update. Environ. Sci. Pollut. Res. 2017, 24, 3274-3297. [CrossRef]

22. Arnold, K.E.; Brown, A.R.; Brown, A.R.; Ankley, G.T.; Sumpter, J.P. Medicating the environment: Assessing risks of pharmaceuticals to wildlife and ecosystems. Philos. Trans. R. Soc. B Biol. Sci. 2014, 369. [CrossRef] [PubMed]

23. Bártíková, H.; Skálová, L.; Stuchĺková, L.; Vokřál, I.; Vaněk, T.; Podlipná, R. Xenobiotic-metabolizing enzymes in plants and their role in uptake and biotransformation of veterinary drugs in the environment. Drug Metab. Rev. 2015, 47, 374-387. [PubMed]

24. Blanco, G.; Junza, A.; Barrón, D. Occurrence of veterinary pharmaceuticals in golden eagle nestlings: Unnoticed scavenging on livestock carcasses and other potential exposure routes. Sci. Total Environ. 2017, 586, 355-361. [CrossRef]

25. Ruiz-Suárez, N.; Melero, Y.; Giela, A.; Henríquez-Hernández, L.A.; Sharp, E.; Boada, L.D.; Taylor, M.J.; Camacho, M.; Lambin, X.; Luzardo, O.P.; et al. Rate of exposure of a sentinel species, invasive American mink (Neovison vison) in Scotland, to anticoagulant rodenticides. Sci. Total Environ. 2016, 569-570, 1013-1021. [CrossRef] [PubMed]

26. Gao, X.; Li, H.; Li, H.; Dong, S.; Chu, J.; Guo, H.; Zhao, Q. Sensitive determination of nine anticoagulant rodenticides in blood by high resolution mass spectrometry with supported liquid extraction pretreatment. Forensic Sci. Int. 2018, 292, 39-44. [CrossRef] [PubMed] 
27. Barron, L.; Tobin, J.; Paull, B. Multi-residue determination of pharmaceuticals in sludge and sludge enriched soils using pressurized liquid extraction, solid phase extraction and liquid chromatography with tandem mass spectrometry. J. Environ. Monit. 2008, 10, 353-361. [CrossRef]

28. Hernández, A.M.; Bernal, J.; Bernal, J.L.; Martín, M.T.; Caminero, C.; Nozal, M.J. Simultaneous determination of nine anticoagulant rodenticides in soil and water by LC-ESI-MS. J. Sep. Sci. 2013, 36, 2593-2601. [CrossRef] [PubMed]

29. Ogilvie, S.C.; Pierce, R.J.; Wright, G.R.G.; Booth, L.H.; Eason, C.T. Brodifacoum residue analysis in water, soil, invertebrates, and birds after rat eradication on Lady Alice Island. N. Z. J. Ecol. 1997, 21, 195-197. [CrossRef]

30. Medvedovici, A.; David, F.; Sandra, P. Determination of the rodenticides warfarin, diphenadione and chlorophacinone in soil samples by HPLC-DAD. Talanta 1997, 44, 1633-1640. [CrossRef]

31. Chen, W.; Geng, M.; Zhang, L.; Xu, L.; Yuan, H.; Li, C.; Peng, C.; Wang, J.; Zhang, M. Determination of coumarin rodenticides in soils by high performance liquid chromatography. Chinese J. Chromatogr. (Se Pu) 2016, 34, 912-917. [CrossRef]

32. Laktičová, K.; Hromada, R.; Ondrašovič, M.; Legáth, J.; Ďurečko, R.; Ondrašovičová, O.; Nowakovic-Dębek, B.; Saba, L. Occurrence of residues of warfarin after its application to cereal crops. Polish J. Environ. Stud. 2009, 18, 405-409.

33. Lee, Y.J.; Choi, J.H.; Abd El-Aty, A.M.; Chung, H.S.; Lee, H.S.; Kim, S.W.; Rahman, M.M.; Park, B.J.; Kim, J.E.; Shin, H.C.; et al. Development of a single-run analytical method for the detection of ten multiclass emerging contaminants in agricultural soil using an acetate-buffered QuEChERS method coupled with LC-MS/MS. J. Sep. Sci. 2017, 40, 415-423. [CrossRef] [PubMed]

34. Ferhi, S.; Bourdat-Deschamps, M.; Daudin, J.J.; Houot, S.; Nélieu, S. Factors influencing the extraction of pharmaceuticals from sewage sludge and soil: An experimental design approach. Anal. Bioanal. Chem. 2016, 408, 6153-6168. [CrossRef] [PubMed]

35. Salvia, M.V.; Vulliet, E.; Wiest, L.; Baudot, R.; Cren-Olivé, C. Development of a multi-residue method using acetonitrile-based extraction followed by liquid chromatography-tandem mass spectrometry for the analysis of steroids and veterinary and human drugs at trace levels in soil. J. Chromatogr. A 2012, 1245, 122-133. [CrossRef] [PubMed]

36. Bragança, I.; Plácido, A.; Paíga, P.; Domingues, V.F.; Delerue-Matos, C. QuEChERS: A new sample preparation approach for the determination of ibuprofen and its metabolites in soils. Sci. Total Environ. 2012, 433, 281-289. [CrossRef] [PubMed]

37. Anastassiades, M.; Lehotay, S.J.; Štajnbaher, D.; Schenck, F.J. Fast and easy multiresidue method employing acetonitrile extraction/partitioning and "dispersive solid-phase extraction" for the determination of pesticide residues in produce. J. AOAC Int. 2003, 86, 412-431. [CrossRef] [PubMed]

38. Perestrelo, R.; Silva, P.; Porto-Figueira, P.; Pereira, J.A.M.; Silva, C.; Medina, S.; Câmara, J.S. QuEChERS-Fundamentals, relevant improvements, applications and future trends. Anal. Chim. Acta 2019, 1070, 1-28. [CrossRef] [PubMed]

39. Asensio-Ramos, M.; Hernández-Borges, J.; Ravelo-Pérez, L.M.; Rodríguez-Delgado, M.A. Evaluation of a modified QuEChERS method for the extraction of pesticides from agricultural, ornamental and forestal soils. Anal. Bioanal. Chem. 2010, 396, 2307-2319. [CrossRef] [PubMed]

40. Vieira, N.M.; Paiva, M.C.G.; da Silva, A.A.; Costa, A.I.G.; de Freitas, F.C.L.; da Costa Marinho, M.I. Validation and application of a QuEChERS based method for estimation of half-life of imidazolinone herbicides in soils by LC-ESI-MS/MS. Ecotoxicol. Environ. Saf. 2018, 167, 212-217. [CrossRef]

41. Acosta-Dacal, A.; Rial-Berriel, C.; Díaz-Díaz, R.; del Mar Bernal-Suárez, M.; Luzardo, O.P. Optimization and validation of a QuEChERS-based method for the simultaneous environmental monitoring of 218 pesticide residues in clay loam soil. Sci. Total Environ. 2021, 753, 142015. [CrossRef]

42. He, Z.; Wang, L.; Peng, Y.; Luo, M.; Wang, W.; Liu, X. Determination of selected polychlorinated biphenyls in soil and earthworm (Eisenia fetida) using a QuEChERS-based method and gas chromatography with tandem MS. J. Sep. Sci. 2015, 38, 3766-3773. [CrossRef]

43. Rouvire, F.; Buleté, A.; Cren-Olivé, C.; Arnaudguilhem, C. Multiresidue analysis of aromatic organochlorines in soil by gas chromatography-mass spectrometry and QuEChERS extraction based on water/dichloromethane partitioning. Comparison with accelerated solvent extraction. Talanta 2012, 93, 336-344. [CrossRef]

44. Cao, X.; Yang, X.; Liu, Z.; Jiao, H.; Liu, S.; Liu, L.; Meng, Q. Rapid Simultaneous Screening and Detection of 12 Anticoagulant Rodenticides in Food by Ultra-performance Liquid Chromatography-Triple Quadrupole/Linear Ion Trap Tandem Mass Spectrometry. Food Anal. Methods 2017, 10, 3538-3547. [CrossRef]

45. Zhu, F.; Liu, H.; Chen, B.; Rong, W.; Ma, Y. Rapid simultaneous screening and detection of ten anticoagulant rodenticides in foods by ultra-high performance liquid chromatography-tandem mass spectrometry. Chin. J. Chromatogr. 2013, 31, 473. [CrossRef] [PubMed]

46. Gómez-Ramírez, P.; Martínez-López, E.; Navas, I.; María-Mojica, P.; García-Fernández, A.J. A modification of QuEChERS method to analyse anticoagulant rodenticides using small blood samples. Rev. Toxicol. 2012, 29, 10-14.

47. Rial-Berriel, C.; Acosta-Dacal, A.; Zumbado, M.; Luzardo, O.P. Micro QuEChERS-based method for the simultaneous biomonitoring in whole blood of 360 toxicologically relevant pollutants for wildlife. Sci. Total Environ. 2020, 736. [CrossRef] [PubMed]

48. Almeida, C.M.M. Overview of Sample Preparation and Chromatographic Methods to Analysis Pharmaceutical Active Compounds in Waters Matrices. Separations 2021, 8, 16. [CrossRef]

49. Vudathala, D.; Cummings, M.; Murphy, L. Analysis of multiple anticoagulant rodenticides in animal blood and liver tissue using principles of QuEChERS method. J. Anal. Toxicol. 2010, 34, 273-279. [CrossRef] [PubMed] 
50. Orfanidis, A.; Gika, H.; Theodoridis, G.; Mastrogianni, O.; Raikos, N. Development of a UHPLC-MS/MS method for the determination of 84 pharmaceuticals and drugs of abuse in human liver. J. Chromatogr. B Anal. Technol. Biomed. Life Sci. 2020, 1151, 122192. [CrossRef] [PubMed]

51. Martínez-Huelamo, M.; Jiménez-Gámez, E.; Hermo, M.P.; Barrón, D.; Barbosa, J. Determination of penicillins in milk using LC-UV, LC-MS and LC-MS/MS. J. Sep. Sci. 2009, 32, 2385-2393. [CrossRef]

52. Hroboňová, K.; Sádecká, J.; Čižmárik, J. HPLC separation and determination of dicoumarol and other simple coumarins in sweet clover. Nov. Biotechnol. Chim. 2018, 17, 95-102. [CrossRef]

53. Hernández, A.M.; Bernal, J.; Bernal, J.L.; Martín, M.T.; Caminero, C.; Nozal, M.J. Analysis of anticoagulant rodenticide residues in Microtus arvalis tissues by liquid chromatography with diode array, fluorescence and mass spectrometry detection. J. Chromatogr. B Anal. Technol. Biomed. Life Sci. 2013, 925, 76-85. [CrossRef]

54. Gallocchio, F.; Basilicata, L.; Benetti, C.; Angeletti, R.; Binato, G. Multi-residue determination of eleven anticoagulant rodenticides by high-performance liquid chromatography with diode array/fluorimetric detection: Investigation of suspected animal poisoning in the period 2012-2013 in north-eastern Italy. Forensic Sci. Int. 2014, 244, 63-69. [CrossRef] [PubMed]

55. Tuerk, J.; Reinders, M.; Dreyer, D.; Kiffmeyer, T.K.; Schmidt, K.G.; Kuss, H.M. Analysis of antibiotics in urine and wipe samples from environmental and biological monitoring-Comparison of HPLC with UV-, single MS- and tandem MS-detection. J. Chromatogr. B Anal. Technol. Biomed. Life Sci. 2006, 831, 72-80. [CrossRef] [PubMed]

56. Taylor, M.J.; Giela, A.; Sharp, E.A.; Senior, C.C.; Vyas, D.S. A rapid multi-class, multi-residue UHPLC-MS/MS method for the simultaneous determination of anticoagulant rodenticides, pesticides and veterinary medicines in wild animals, pets and livestock. Anal. Methods 2019, 11, 1087-1101. [CrossRef]

57. Bourdat-Deschamps, M.; Leang, S.; Bernet, N.; Daudin, J.J.; Nélieu, S. Multi-residue analysis of pharmaceuticals in aqueous environmental samples by online solid-phase extraction-ultra-high-performance liquid chromatography-tandem mass spectrometry: Optimisation and matrix effects reduction by quick, easy, cheap, effective, rugged and safe extraction. J. Chromatogr. A 2014, 1349, 11-23. [CrossRef] [PubMed]

58. SANTE/12682 Guidance document on analytical quality control and validation procedures for pesticide residues analysis in food and feed. Eur. Comm. Health Consum. Prot. Dir. 2019, 2-44. Available online: https://www.eurl-pesticides.eu/docs/public/ tmplt_article.asp?CntID=727 (accessed on 8 March 2021).

59. Lehotay, S.J.; O’Neil, M.; Tully, J.; García, A.V.; Contreras, M.; Mol, H.; Heinke, V.; Anspach, T.; Lach, G.; Fussell, R.; et al. Determination of pesticide residues in foods by acetonitrile extraction and partitioning with magnesium sulfate: Collaborative study. J. AOAC Int. 2007, 90, 485-520. [CrossRef]

60. Acosta-Dacal, A.; Rial-Berriel, C.; Díaz-Díaz, R.; del Mar Bernal-Suárez, M.; Zumbado, M.; Henríquez-Hernández, L.A.; Luzardo, O.P. Supporting dataset on the optimization and validation of a QuEChERS-based method for the determination of 218 pesticide residues in clay loam soil. Data Br. 2020, 33, 106393. [CrossRef] [PubMed]

61. SANCO/825/00 Guidance Document on Pesticide Residue Analytical Methods. 2010. Available online: https://ec.europa.eu/ food/sites/food/files/plant/docs/pesticides_ppp_app-proc_guide_res_post-reg-cont-monitor.pdf (accessed on 8 March 2021).

62. Raposo, F. Evaluation of analytical calibration based on least-squares linear regression for instrumental techniques: A tutorial review. TrAC Trends Anal. Chem. 2016, 77, 167-185. [CrossRef]

63. Kamel, A.M.; Brown, P.R.; Munson, B. Effects of mobile-phase additives, solution pH, ionization constant, and analyte concentration on the sensitivities and electrospray ionization mass spectra of nucleoside antiviral agents. Anal. Chem. 1999, 71, 5481-5492. [CrossRef]

64. King, R.; Bonfiglio, R.; Fernandez-Metzler, C.; Miller-Stein, C.; Olah, T. Mechanistic investigation of ionization suppression in electrospray ionization. J. Am. Soc. Mass Spectrom. 2000, 11, 942-950. [CrossRef]

65. Kruve, A.; Kaupmees, K. Adduct Formation in ESI/MS by Mobile Phase Additives. J. Am. Soc. Mass Spectrom. 2017, 28, 887-894. [CrossRef] [PubMed]

66. Danaher, M.; O’Keeffe, M.; Glennon, J.D.; Howells, L. Development and optimisation of an improved derivatisation procedure for the determination of avermectins and milbemycins in bovine liver. Analyst 2001, 126, 576-580. [CrossRef] [PubMed] 